\title{
SEVERAL GEOTECHNICAL DESIGN AND CONSTRUCTION ISSUES WITH AKASHI STRAIT BRIDGE
}

\author{
KoJI Kawaguchi ${ }^{\text {i) }}$ and Fumio TATSUOKa ${ }^{\text {ii) }}$
}

\begin{abstract}
The Akashi Kaikyo (Strait) Bridge, one of the major bridges of the Honshu-Shikoku bridge network connecting the main island and the Shikoku island, is the world's longest suspension bridge with a center span of about 2,000 $\mathrm{m}$. The bridge was constructed over the Akashi Strait and opened to traffic in 1998 after a construction period of about 10 years. The granite stratum in the Akashi Strait was very deep, while the granite stratum provides the foundations for the other long span bridges which have been constructed in Japan. Three of the four foundations had to be constructed on either a weakly cemented gravelly soil deposit or a sedimentary soft rock layer. The geological structure was carefully investigated and the geotechnical properties, in particular the strength and deformation characteristics of these geomaterial types, were carefully evaluated. To this end, a comprehensive series of advanced triaxial compression (TC) tests were performed on rotary core tube samples of sedimentary soft rock after it was found that the due design was not possible based on unconfined compression tests. Both CD and CU TC tests and cyclic undrained triaxial tests were performed on rotary core tube samples $(30 \mathrm{~cm}$ in dia.) of the gravelly soil. Based on the data, the long-term and seismic stabilities of the foundations were evaluated. The importance of strain- and pressure-dependent nonlinear stress-strain behaviour at small strains, as well as accurate strain measurements in the laboratory stress-strain tests, was confirmed by analyzing the full-scale behaviour of the foundation during and after construction and comparing the back-calculated stiffness values with those obtained from laboratory stress-strain tests, pressure-meter tests, plate loading tests and field shear wave velocity measurements.
\end{abstract}

Key words: bridge foundations, gravelly soil, sedimentary soft rock, settlement, small strains, triaxial test (IGC: $\mathrm{E} 3 / \mathrm{H} 1)$

\section{INTRODUCTION}

The Akashi Kaikyo (Strait) Bridge, constructed over Akashi Strait to link Kobe City and Awajishima Island, is the world-longest suspension bridge with a total length of $3,911 \mathrm{~m}$ and a center span of 1,991 m (Figs. 1 and 2, Photo. 1). Akashi Strait, which is used by over 1,400 vessels a day, is about $4 \mathrm{~km}$-wide and has a maximum depth of $110 \mathrm{~m}$. The bridge has two piers ( $2 \mathrm{P}$ and $3 \mathrm{P})$ and two anchorages (1A and 4A) (Fig. 2). The seabed consists of surface deposits of recent Holocene and upper Pleistocene, underlain by Akashi Formation (gravelly soil) of Pleistocene to Pliocene and/or Kobe Formation (sedimentary soft rock) of Miocene, underlain by a granite bedrock (Fig. 2). The Akashi Formation was formed probably by mud flows from several million years ago in the Late Neogene Period of the Tertiary Era to the Early Pleistocene Period. This gravelly soil is well-graded and weakly cemented, consisting of round gravel particles originated from ancient river beds and a matrix of fine soils. The largest thickness was about $50 \mathrm{~m}$. Kobe Formation consists of sedimentary soft rock (SSR) with alternative thin layers of sandstone and mud-stone, formed during the early Neogene Period. Anchorage 1A and Pier 3P were constructed on Kobe Formation, while

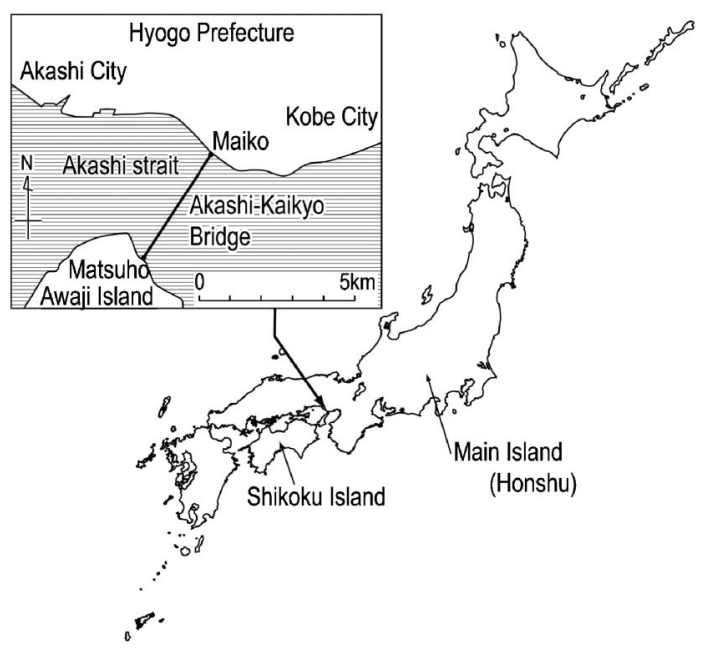

Fig. 1. Location of Akashi Kaikyo (Strait) Bridge

i) Honshu-Shikoku Bridge Expressway Co. Ltd., Japan.

ii) Professor, Tokyo University of Science, Japan (tatsuoka@rs.noda.tus.ac.jp).

The manuscript for this paper was received for review on September 3, 2010; approved on October 1, 2010. 


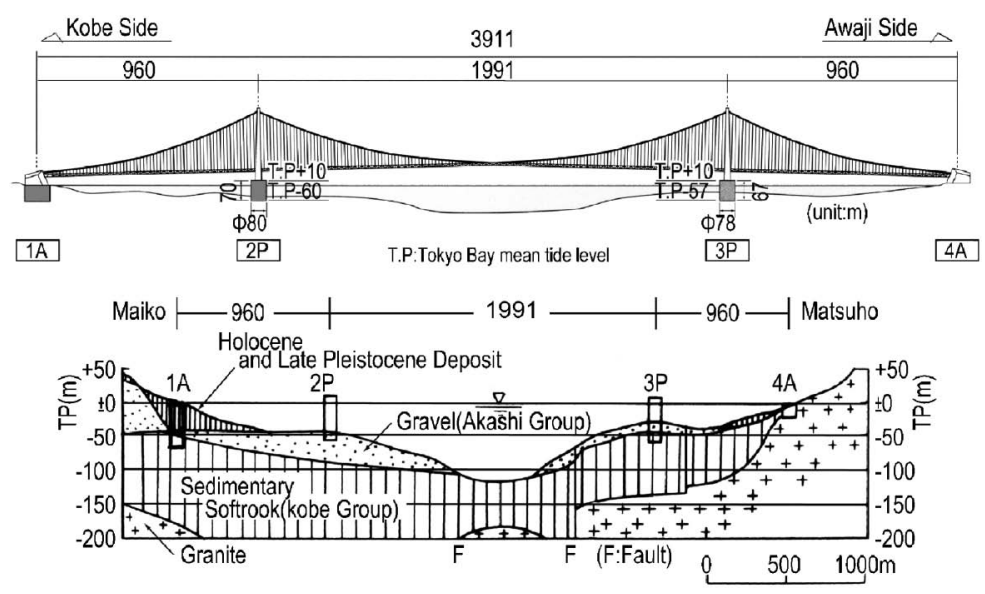

Fig. 2. Plan and geological conditions

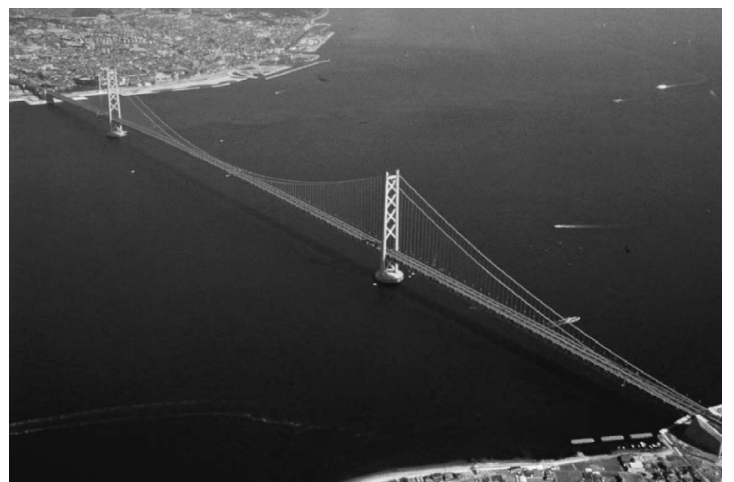

Photo. 1. Picture of Akashi Kaikyo (Strait) Bridge

Pier 2P on Akashi Formation and Anchorage 4A on weathered granite.

The foundations for most of the previous long span bridges constructed in Japan, such as the Seto-Ohashi Bridge, are placed on weakly weathered granite. For the design of those foundations, bedrock zoning was conducted according to the bedrock classification standard based on observations of core samples while referring to results from pressure-meter tests, geophysical logging and rock tests. The geotechnical design parameters were determined by plate loading tests (PL tests), block shearing tests, creep tests etc. conducted at on-land similar grounds. However, it was found that these tests cannot provide sufficient data for the design of Akashi Strait Bridge. To predict the instant displacement (i.e., settlement and tilting) during construction, the long-term residual displacements under static working loads and the seismic stability of the foundations, which were among the major concerns at the design stage, it was necessary to evaluate the strength and deformation characteristics of the gravelly soil and SSR by relevant laboratory stressstrain tests.

\section{FOUNDATIONS}

Anchorage 1A, located at the reclaimed working yard along the shore line of Kobe side, is founded on Kobe SSR, comprising an underground circular diaphragm wall fully filled with roller compacted concrete (Fig. 3). Anchorage 4A, located at the Awajishima side, comprises a rectangular shallow foundation with the main body filled with roller compacted concrete. The two piers, 2P (on Akashi gravelly soil) and 3P (on Kobe SSR), are underwater solid cylindrical foundations constructed at sites continuously subjected to swift tidal current in a very deep sea. A circular cross-sectional shape was chosen to resist this swift tidal current. A simple structure was chosen for better constructability and easier estimation of the bearing capacity. Successful construction of these piers was one of the critical technical factors for the success of the entire project. Therefore, a comprehensive series of rather sophisticated advanced field and laboratory geotechnical investigations were performed.

The two piers were constructed as follows. Firstly, the ground was excavated to a depth with sufficient bearing capacity by using a large grab dredge. For stable and efficient excavation in swift tidal current, three types of heavy grab buckets were used. A light type with a bucket weight of 85 tonf and a heavy type (125 tonf) were used to excavate the Akashi gravelly soil stratum for Pier 2P, while ultra heavy types (150 tonf and 200 tonf), with a larger excavation capacity, were used to excavate the Kobe SSR stratum for Pier 3P. Secondly, a pair of steel caissons, which were used as a steel form for the underwater casting of concrete, were manufactured in a shipbuilding dock at a remote place and towed to the sites by tug boats. After the caissons were moored, sea water was poured into the inside of the double wall of the steel caissons. The final exact positioning on the supporting ground was achieved by operating winches mounted on the respective caissons. Thirdly, to prevent erosion in the seabed by the strong tidal current adjacent to the caissons, filter units comprised of steel mesh containers packed with riprap were arranged adjacent to the caissons and overlain by rubble. Lastly, underwater concrete with a high flowability and a high resistance to segregation under water was cast into the inside of the caissons using a 

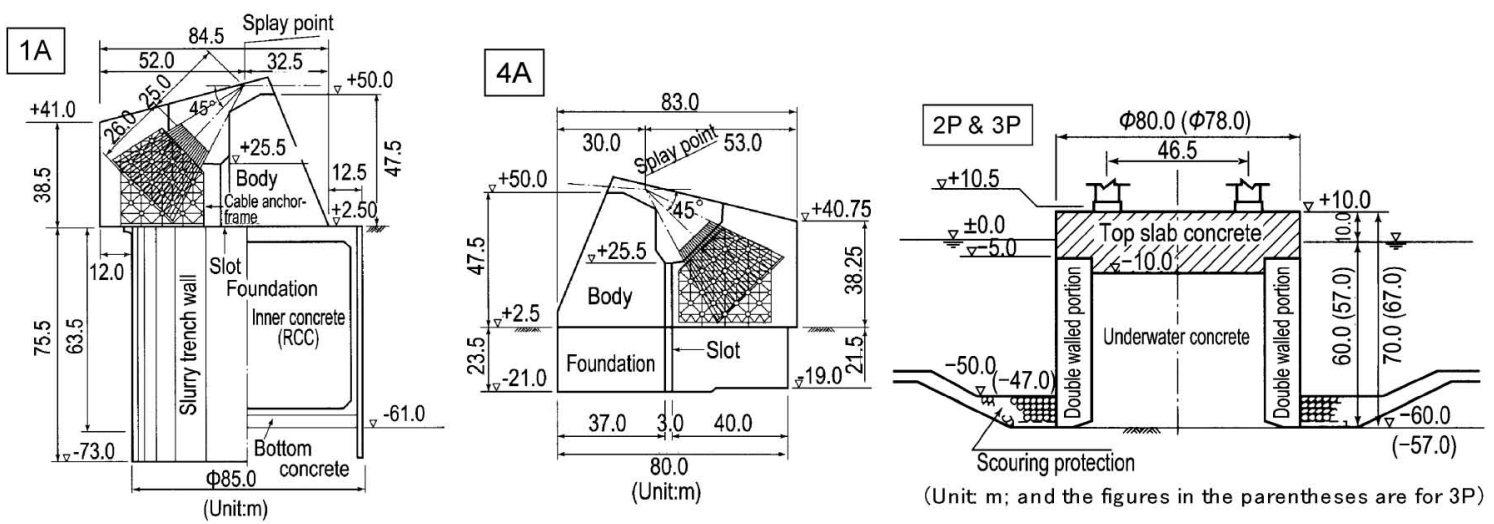

Fig. 3. Four foundations

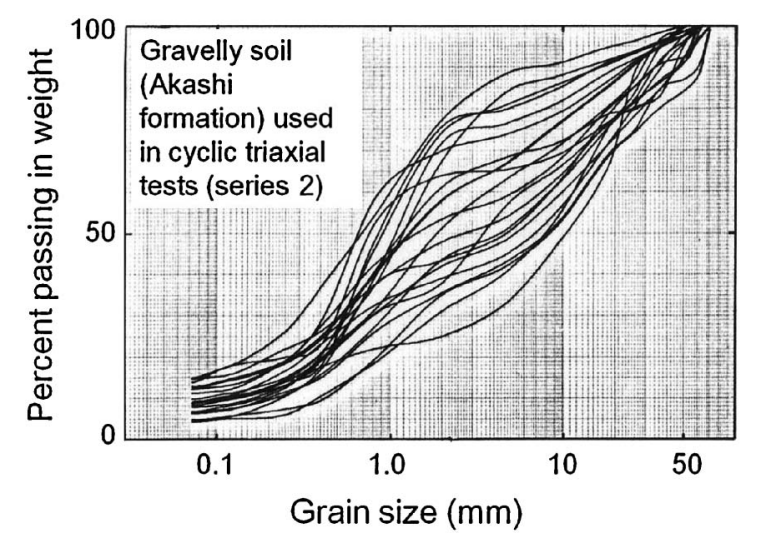

Fig. 4. Grading curves of Akashi gravelly soil (Tatsuoka et al., 1991)

large barge equipped with a concrete plant and another large barge used for stocking a large volume of materials.

\section{GEOLOGICAL SURVEY AND GEOTECHNICAL INVESTIGATION}

At the planning stage, in about 1960, a number of geological surveys were performed to collect the necessary topological and geological information for the selection and comparison of several feasible bridge routes. The final detailed geological survey and geotechnical investigation was conducted over a two year period, from 1986 to 1987 , after the locations of the four foundations were determined. A number of borings ( 38 in total with a total length of 2,420 m) were made at the foundation sites at a separation of basically $15-30 \mathrm{~m}$. In the bore holes, a number of pressure-meter tests (PM tests) interpreting the primary loading results by the linear theory (in total 376), PS wave loggings, electrical loggings, and density loggings were performed. It was recognized, however, that such field tests in the bore holes are not sufficient to confidently evaluate the strength and deformation characteristics of Akashi gravelly soil and Kobe SSR that are necessary to determine the depth and size of Piers $2 \mathrm{P}$ and $3 \mathrm{P}$. For this reason, despite a very high cost involved, a number of 'undisturbed' samples for laboratory stressstrain tests were retrieved from the ground by means of newly developed triple tube rotary core tube sampling methods with a sample diameter of $116 \mathrm{~mm}$ for SSR and $300 \mathrm{~mm}$ for gravelly soil. Off-shore undisturbed sampling at depths of down to about $40 \mathrm{~m}$ below the seabed was performed from a huge self-elevating platform. Figure 4 shows the grain size distributions of the samples of Akashi gravelly soil used for the cyclic undrained triaxial tests explained later.

\section{EVALUATION OF GEOTECHNICAL PROPERTIES}

\section{Kobe Sedimentary Soft Rock (SSR)}

At the beginning stage of the design, the unconfined compression test (the $\mathrm{U}$ test) was the most popular laboratory stress-strain test to evaluate the strength and deformation characteristics of soft rock in engineering practice in Japan. This may be because the effects of confining pressure on the strength and deformation characteristics of soft rock are not obvious, while it is usually difficult to recognize several inherent serious problems with the $\mathrm{U}$ test. This is explained below. Also in this project, a large number of $U$ tests were performed on core samples of Kobe SSR obtained by rotary core tube sampling on shore sites and at the foundation sites. Figure 5 shows the summary of unconfined compression strength $q_{\mathrm{u}}$. The scatter of the $q_{\mathrm{u}}$ values is extremely large while the average is very low. It was a serious problem at that time because, if the design had been made based on these $q_{\mathrm{u}}$ values, the foundations would have been too large and deep, and therefore, the costs would have been unacceptable.

In 1983, a geotechnical investigation of Kobe SSR was performed near the Anchorage 4A site (Fig. 6). The $q_{\mathrm{u}}$ values from these tests also scattered very broadly, while the respective compressive strengths $q_{\max }$ from the CU TC tests on the core samples isotropically re-consolidated to respective field effective vertical stresses $\sigma_{v}^{\prime}$ (in-situ) were generally much larger than the $q_{\mathrm{u}}$ value at a similar depth. Figure 7 compares several pairs of $q_{\mathrm{u}}$ and $q_{\max }$ values of core samples obtained respectively at nearly the same depth at the described in Fig. 6, obtained by another in another series of tests performed at the University of Tokyo. For the CU TC tests, the samples were re-consoli- 
dated isotropically to $\sigma_{\mathrm{v}}^{\prime}$ (in-situ). The respective $q_{\mathrm{u}}$ values were substantially smaller than the corresponding $q_{\max }$ value, while the ratio $q_{\max } / q_{\mathrm{u}}$ scattered enormously. The effect of effective confining pressure on the shear strength of Kobe SSR can also be seen from the relatively large values of $\phi$ (by the total stress method) from the CU TC tests (Fig. 6). These test results indicated that the large scatter in the $q_{\mathrm{u}}$ values seen in Figs. 5 and 6 is due not only to an intrinsic difference in the strength between
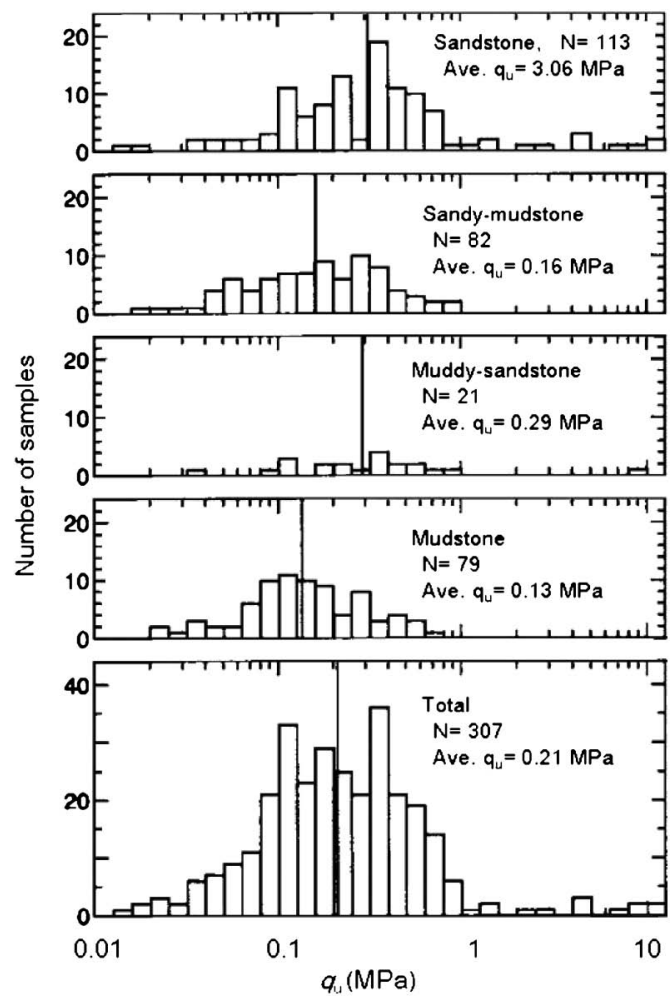

Fig. 5. Distributions of $q_{\mathrm{u}}$ of rotary core tube samples of SSR (complied in 1985, Tatsuoka and Kohata, 1995) mudstone and sandstone, but also to large and varying effects of sample disturbance and no confinement among the different $\mathrm{U}$ tests. Based on this result, it was decided that these $q_{\mathrm{u}}$ values are utterly unreliable and the average value largely underestimates the in-situ strength. In what followed, a large number of CU and CD TC tests were performed on core samples obtained by triple-tube rotary core sampling with a sample diameter of $116 \mathrm{~mm}$ from the sites (Figs. 8(a) and (b)). The sandstone was generally stronger than the mudstone, exhibiting a clear trend of strain softening. The design shear strength parameters were determined by reducing the measured peak strengths after taking this factor into account. The CU TC strength was used for the seismic stability analysis of these foundations and the $\mathrm{CD}$ strength was used for the long-term

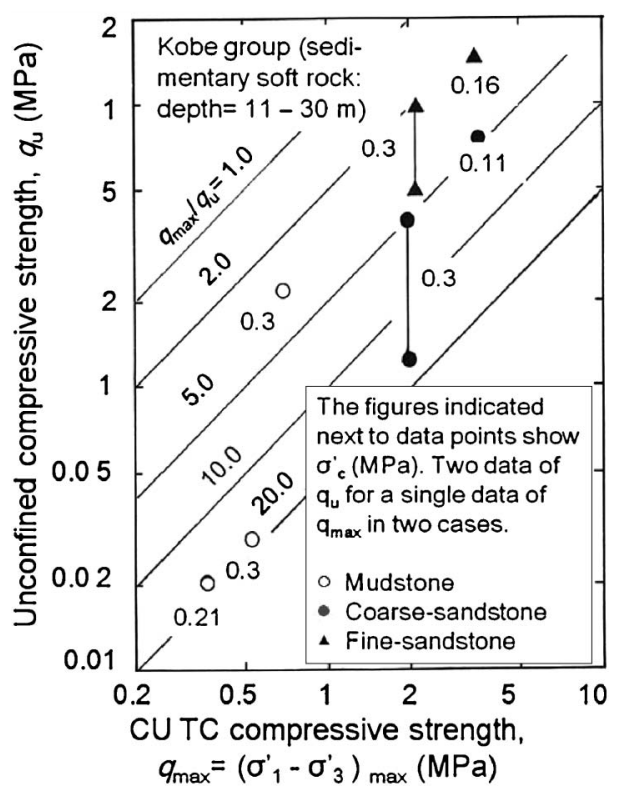

Fig. 7. Comparison of compressive strength between $U$ and $C U$ TC tests of SSR, Matsuho site (Tatsuoka and Kohata, 1995)

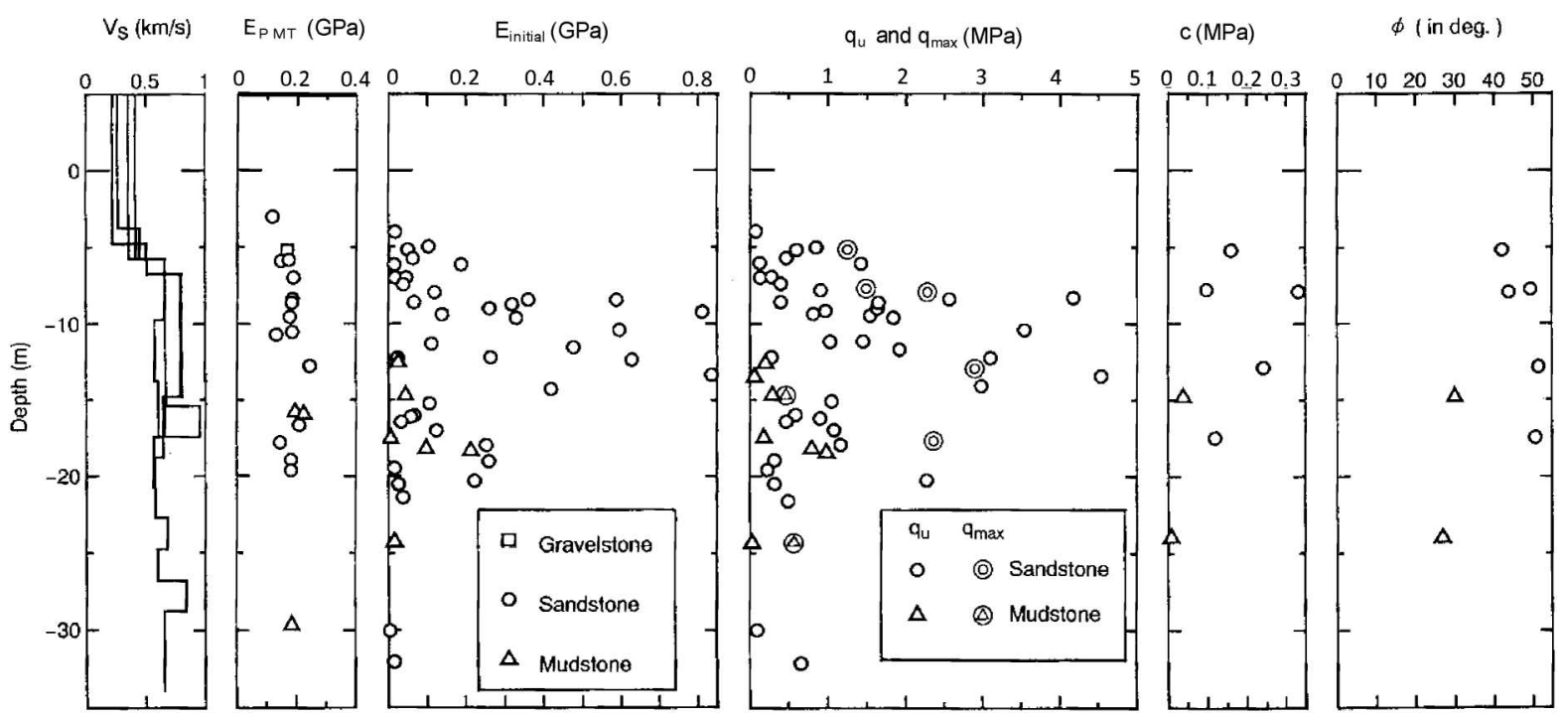

Fig. 6. A typical geotechnical profile of Kobe Formation, Matsuho site, near Anchorage 4A (Tatsuoka and Kohata, 1995) 
a)

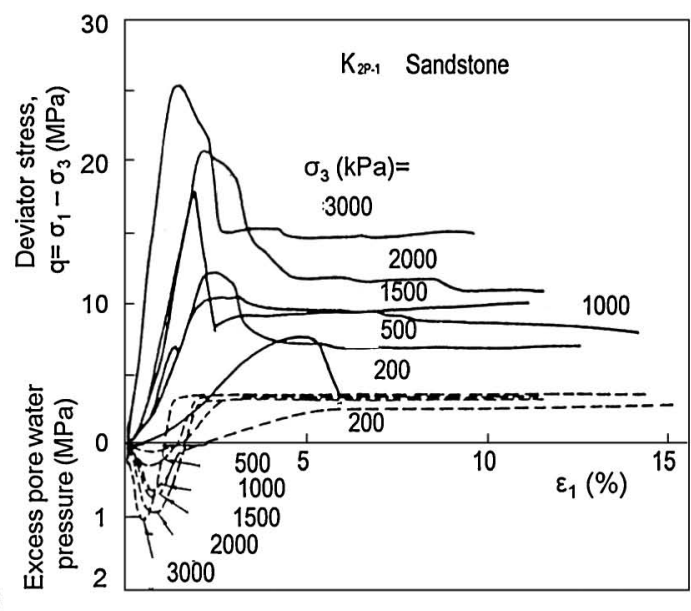

b)

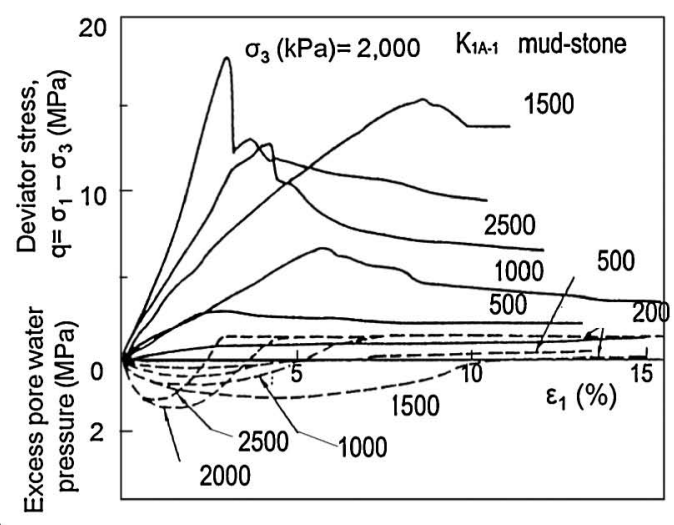

Fig. 8. Typical CU TC tests on Kobe SSR: a) sandstone; and b) mudstone (Yamagata et al., 1995a)

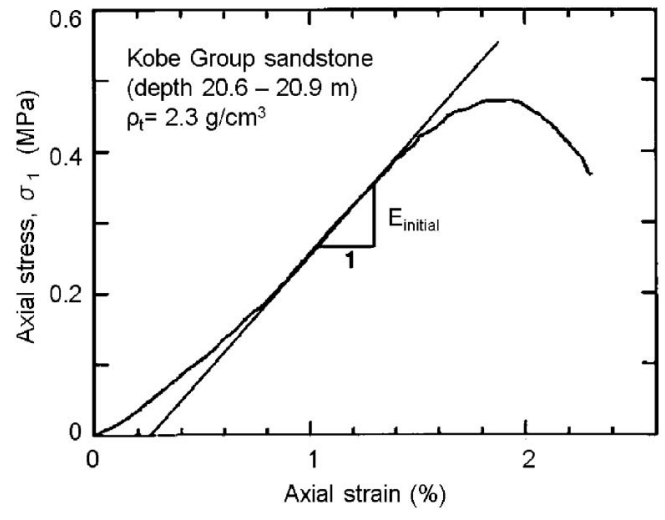

Fig. 9. Axial stress-axial strain relation from a typical U test of Kobe SSR (sandstone) from Matsuho site (Tatsuoka and Kohata, 1995)

stability analysis.

Figure 6 also presents the initial Young's modulus, $E_{\text {initial }}$, defined as the maximum tangent modulus of the axial stress-axial strain curve from the U tests (Fig. 9). The scatter of the $E_{\text {initial }}$ values is also significant and some values are extremely low. However, the local apparent linearity of the stress-strain relation, as seen in Fig. 9, does not indicate the linear elastic property of the material, but is simply an intermediate part of an S-shaped stress-strain relation resulting from micro-cracks in a specimen that developed during sampling and handling as well as bedding error at the top and bottom ends of the specimen. These $E_{\text {initial }}$ values, with an average of 0.21 $\mathrm{GPa}$, are extremely low, substantially lower than the true elastic modulus (as shown below). It was judged that the $E_{\text {initial }}$ values from the $\mathrm{U}$ tests were not reliable and could not be used in the design.

Figure 10 summarizes the Young's modulus values from different field and laboratory tests of Kobe SSR (of a geological age of about 4 million years) at the site of Anchorage $1 \mathrm{~A}$. The $E_{\text {initial }}$ values from $\mathrm{U}$ tests using rotary core tube samples largely scatter, like the data presented in Fig. 6, while the values from the PM tests $\left(E_{\mathrm{PMT}}\right)$ are only marginally larger than these $E_{\text {initial }}$ values, and the values from the plate loading tests $\left(E_{\mathrm{PLT}}\right)$ performed at the final bottom of excavation (at a depth of $61.5 \mathrm{~m}$ ) are noticeably larger than the $E_{\text {initial }}$ values. These $E_{\mathrm{PLT}}$ values are the tangent modulus, which depends on the pressure level at which the value is defined, as will be discussed later. As all these Young's modulus values were obtained by static loading tests which apply or measure stresses (or loads) and strains (or displacements), these Young's modulus values were, and are, often called "the static elastic modulus". At the design stage, a decision based on experience was made that these $E_{\text {initial }}$ values were too low to be used in a prediction of footing settlement. Some engineers were even of the opinion that the laboratory stress-strain tests are generally not reliable. It was decided to predict the instant footing settlements by the linear theory using the $E_{\mathrm{PLT}}$ values converted from the $E_{\mathrm{PMT}}$ values measured at the footing sites based on the empirical relationship between the $E_{\mathrm{PLT}}$ and $E_{\mathrm{BHLT}}$ values obtained at on-shore sites (Yamagata et al., 1995a). On the other hand, a group of vertical short lines presented in Fig. 10 represent the Young's modulus values $\left(E_{\mathrm{f}}\right)$ from in-situ shear wave velocities from PS logging by the suspension method. These $E_{\mathrm{f}}$ values are substantially larger than "the static elastic modulus values" described above. The $E_{\mathrm{f}}$ value were, and are, often called "the dynamic elastic modulus"'. Due to the substantial difference between "this dynamic elastic modulus" and "the static elastic modulus", it was usual at that time for these $E_{\mathrm{f}}$ values to be used only in earthquake response analysis, but not referred to in the prediction of footing settlements. However, the separation between the 'static' and 'dynamic' values of the Young's modulus is only apparent, as is shown below.

At the bottom of the excavation for Anchorage A1, undisturbed samples were retrieved by block sampling and a series of advanced CD TC tests was performed at the University of Tokyo (Fig. 11). The samples were reconsolidated isotropically to $\sigma_{\mathrm{v}}^{\prime}$ (in-situ) $=0.51 \mathrm{MPa}$ (the value before excavation). The axial strains were measured 


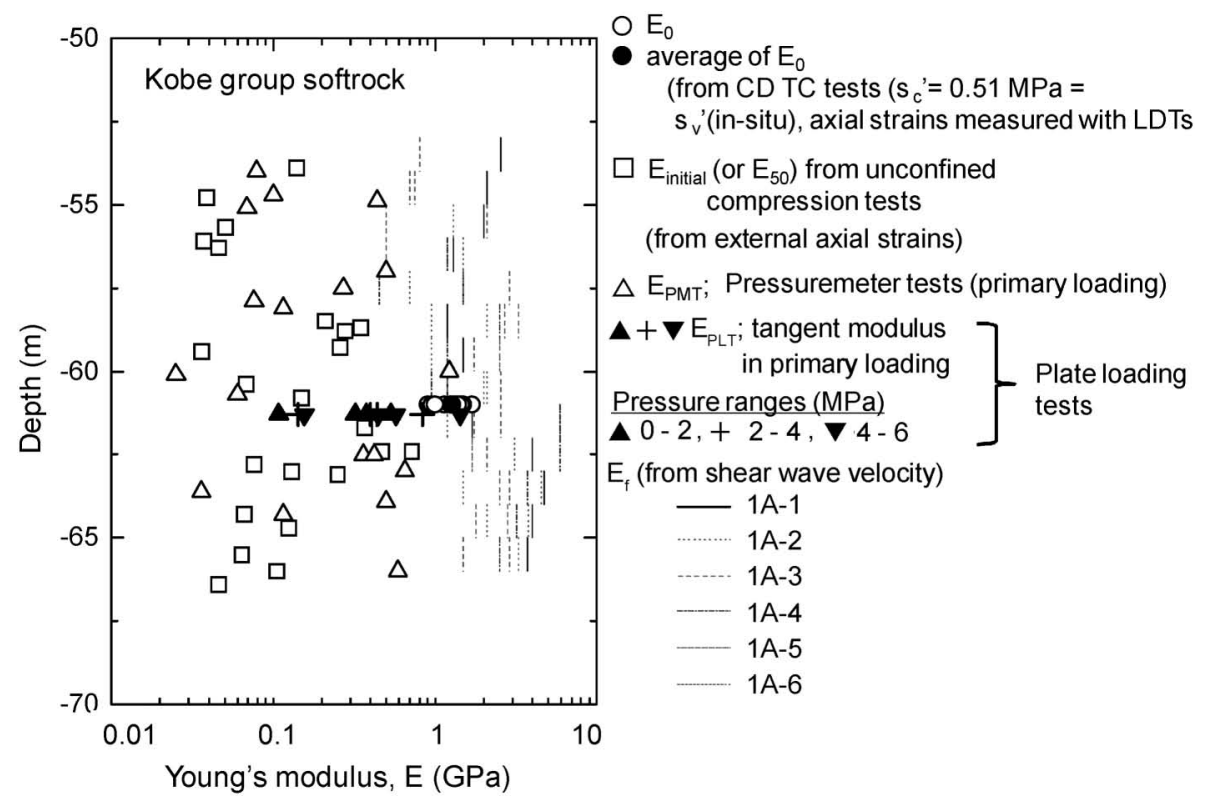

Fig. 10. Distributions of Young's modulus from different field and laboratory tests, SSR (sandstone), Anchorage 1A site (the plate diameter in PLT $=60 \mathrm{~cm}$; Tatsuoka et al., 1999)
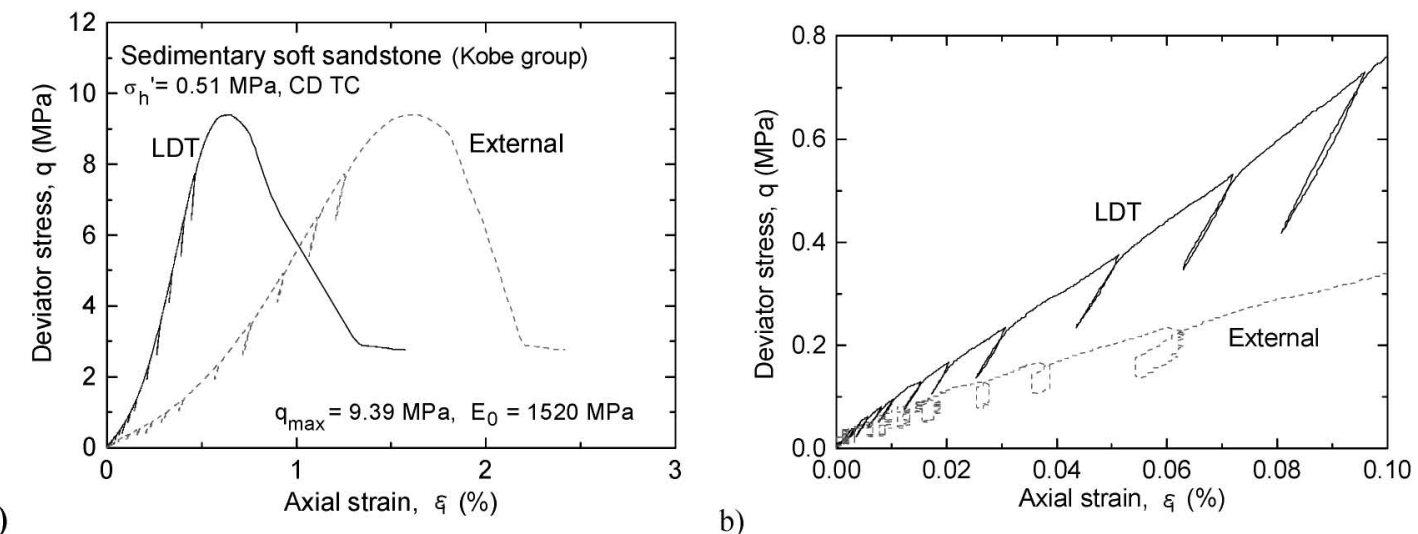

a)

b)

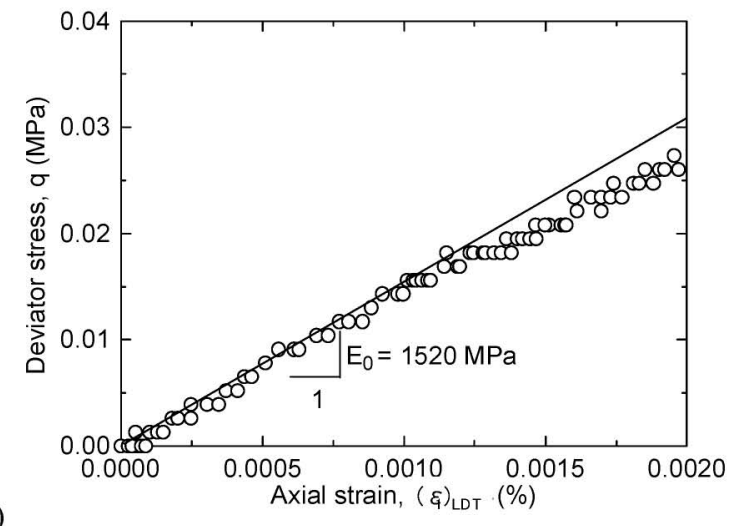

d)

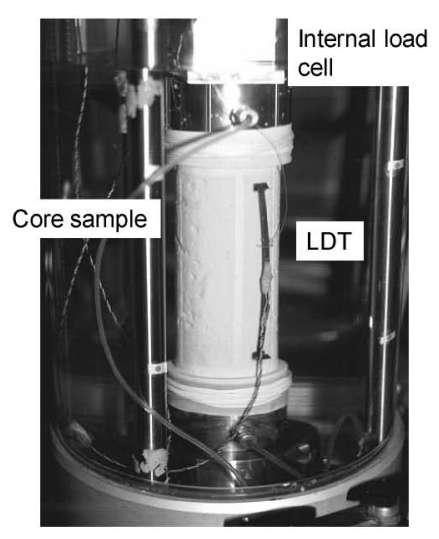

Fig. 11. a)-c) A typical CD TC test of Kobe SSR at Anchorage 1A site; and d) a CD TC test with local strain measurements (Tatsuoka et al., 1999)

both externally from the axial displacements of the loading piston and locally by means of a pair of local deformation transducers, LDTs (Fig. 11(d)) (Goto et al., 1991). The very large discrepancy seen between the externally and locally measured axial strains (Figs. 11(a) and (b)) is due to bedding error at the specimen top and bottom. The initial slope of the deviator stress-locally measured axial strain relation is defined as the initial Young's modulus at very small strains, $E_{0}$ (Fig. 11(c)). As seen from Fig. 10 , the $E_{0}$ values from a set of CD TC tests are 
similar to the $E_{\mathrm{f}}$ values at the same depth. More precisely, the average value of $E_{0}$ is smaller by a factor $1 / 1.36$ than the average value of $E_{\mathrm{f}}$ at the same depth (excluding one exceptionally large value). This difference is due partly to a difference between the drained and undrained Poisson's ratios (i.e., 0.3 and 0.46) (Tatsuoka and Kohata, 1995) and partly to the effect of sample disturbance. This fact indicates that the difference between "the static elastic modulus, $E_{\text {initial }}, E_{\mathrm{PMT}}$ or $E_{\mathrm{PLT}}$ " and "the dynamic elastic modulus, $E_{\mathrm{f}}$ '" is due basically to either or all of the following factors: 1) largely different strain levels at which these values are evaluated; 2) the effects of sample disturbance in laboratory stress-strain tests; and 3) the effects of bedding error in externally measured axial strains in laboratory stress-strain tests and displacements in PM tests and PL tests. It was found after the completion of the bridge that the instant footing settlement can be rather accurately evaluated using these $E_{\mathrm{f}}$ values while taking into account a high non-linearity by strain and pressure of stress-strain behaviour evaluated by TC tests, as shown later.

\section{Akashi Gravelly Soil}

The seismic design of Pier $2 \mathrm{P}$, which was much more was comprised of two stages. At the first stage, a pseudostatic limit equilibrium stability analysis was performed sophisticated than those for ordinary bridge foundations,

based on the results from about fifty CD and CU TC tests on rotary core tube samples $(30 \mathrm{~cm}$ in diameter and $60 \mathrm{~cm}$ high). Figure 12 shows typical test results. Figure 13(a) shows a Mohr-Coulomb failure envelope from the CD

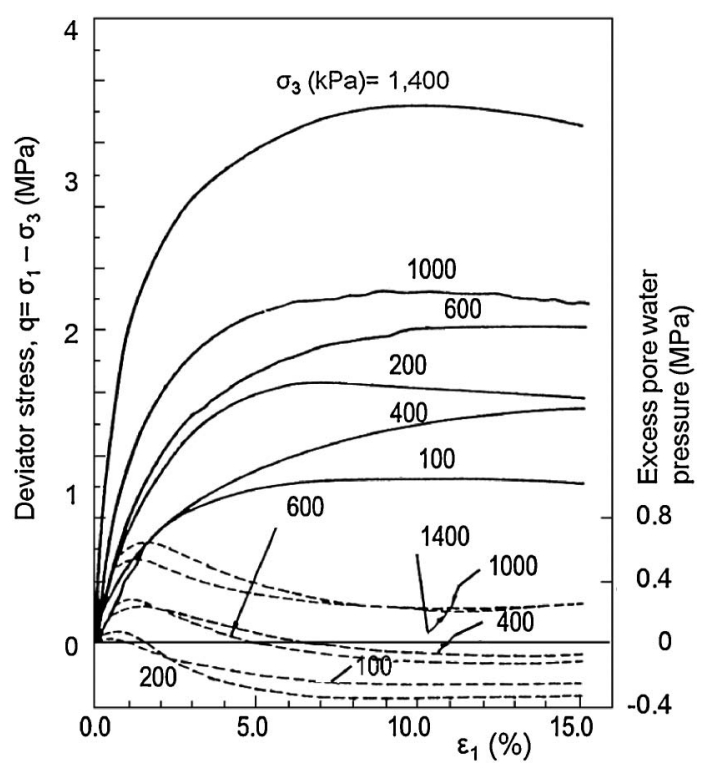

Fig. 12. Typical CU TC tests on Akashi gravelly soil (Yamagata et al., 1995a)

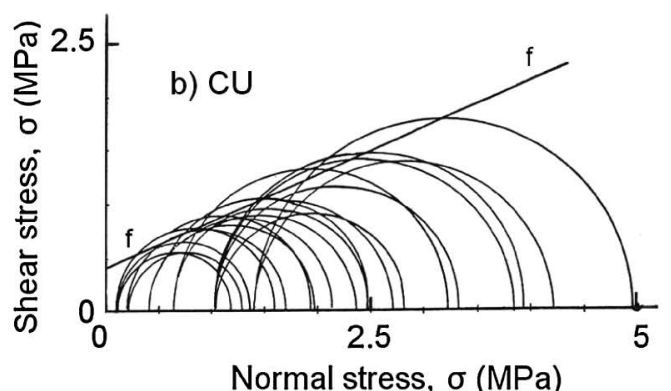

b)

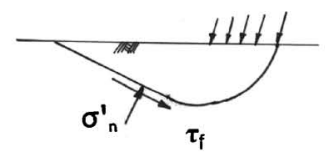

c)

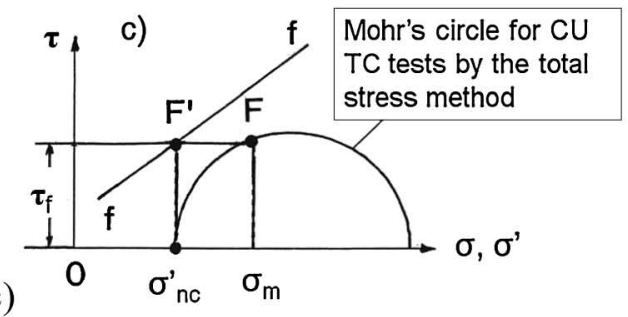

d)

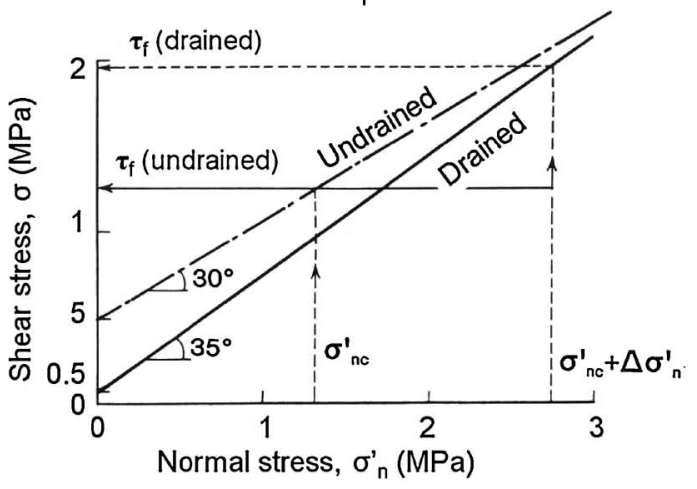

Fig. 13. Mohr's circles of stress at failure of isotropically consolidated samples and failure envelops: a) CD TC; b) CU TC (Yamagata et al., 1995a); c) definition of shear and normal stresses along the failure plane ( $\tau_{\mathrm{f}}$ and $\sigma_{\mathrm{m}}$ ) for CU TC tests; and d) drained and undrained design shear strengths for pseudo-static stability analysis 
TC tests for long-term static stability analysis of Pier $2 \mathrm{P}$. It had been common practice in the seismic design of bridge foundations on gravelly soil to use drained shear strengths along a given failure plane obtained by substituting the effective normal stress at failure, equal to the initial effective normal stress $\sigma_{\text {nc }}^{\prime}$ plus a change (positive or negative) by seismic load $\Delta \sigma_{\text {nc }}^{\prime}$, into the drained failure envelope. In this project, however, the undrained shear strength $\tau_{\mathrm{f}}$, which is equal to the value corresponding to the mean principal stress $\sigma_{\mathrm{m}}$ along the Mohr's circle of stress at failure, defined in Fig. 13(c), was used. To this end, the value of $\tau_{\mathrm{f}}$ from the respective CU TC tests was plotted against the initial effective normal stress $\left(\sigma_{\mathrm{nc}}^{\prime}\right)$, which is equal to the isotropic effective confining pressure in this case. A straight line f-f depicted in Fig. 13(b) is the undrained failure envelope fitted to the data points. Figure 13(d) shows the drained and undrained failure envelopes used in the design, determined conservatively based on these test results.

At the second stage, the residual displacements of the footing under plane strain conditions in the transversal direction of the bridge, which is least stable during an earthquake, were evaluated by numerical analysis based on results from sixteen cyclic undrained triaxial tests on rotary core tube samples consolidated to different

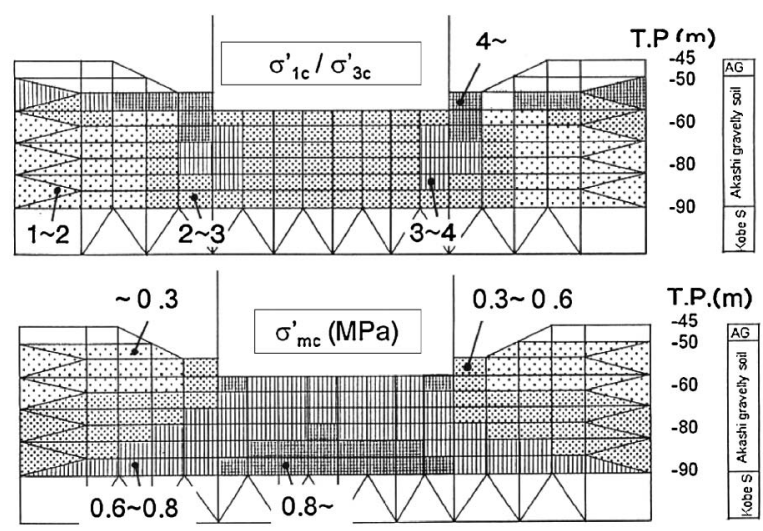

Fig. 14. Initial effective stress conditions from static FEM analysis (AG: Alluvial gravel; and Kobe S: Kobe sedimentary soft rock; Tatsuoka et al., 1991)

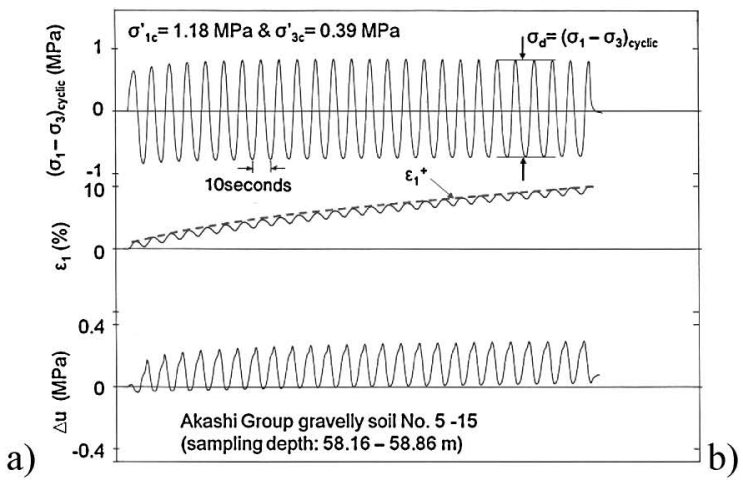

anisotropic stress states (i.e., $\sigma_{1 \mathrm{c}}^{\prime} / \sigma_{3 \mathrm{c}}^{\prime}=2,3$ and 4 at an effective mean principal stress $\sigma_{\mathrm{mc}}^{\prime}=0.67 \mathrm{MPa}$ ), followed by undrained TC toward ultimate failure in five tests. Similar tests were performed at an isotropic stress state of $\sigma_{\mathrm{mc}}^{\prime}=0.4 \mathrm{MPa}$. These effective consolidation stress states were selected to be representative of the initial effective stress conditions evaluated by static FEM analysis (Fig. 14). The samples were lightly cemented with void ratios of less than 0.5. A typical test result is presented in Fig. 15(a). Figure 15(b) presents a summary of the number of loading cycles $N_{\mathrm{c}}$ to reach different peak axial strains (denoted as $\varepsilon_{1}^{+}$in Fig. 15(a)) when subjected to different cyclic deviator stresses for one of the specified initial stress condition. $\varepsilon_{1}^{+}$was used in the analysis to predict residual displacements of the footing, as shown below. Similar strength curves for different initial effective stress states were prepared. It was assumed that a decrease in the strength by the deviation of the initial major principal stress direction from the vertical direction and continuous rotation of the principal stresses during an earthquake is compensated for by a decrease in the strength by sample disturbance and sampling from depths shallower (therefore, geologically younger) than those at which the $\varepsilon_{1}^{+}$values are evaluated.

The $\varepsilon_{1}^{+}$values that would take place at respective points in the supporting gravelly soil deposit during the specified design seismic load were estimated by the cumulative damage concept (e.g., Tatsuoka et al., 1986, 1991) as follows. Firstly, the time histories of deviator stress at many representative points in the supporting ground of Pier $2 \mathrm{P}$ were obtained, as shown in Fig. 16, by an equivalent linear FEM earthquake response analysis of the foundation and ground system using shear strain-dependent shear modulus and damping ratio evaluated by cyclic drained triaxial tests on core samples (Fig. 17). The input time history of horizontal acceleration (Fig. 18) was given at the engineering bedrock at the site (i.e., the top of unweathered granite). Secondly, a series of half pulse cyclic deviator stress in the respective time histories of deviator stress (Fig. 16) was obtained (Fig. 19(a)). The nth largest pulse of [peak of $\left.\left(\sigma_{1}-\sigma_{3}\right)_{\text {cyclic }}\right] /\left(2 \sigma_{\mathrm{mc}}^{\prime}\right)$ is denoted as SR(n), where SR(1) is the largest SR(n). Thirdly, for each element, by using respective pulse distributions (Fig.

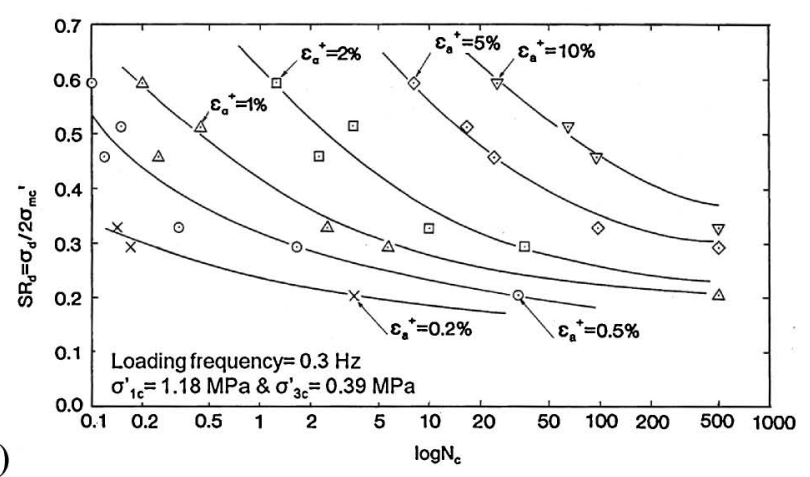

Fig. 15. a) Typical time histories of cyclic deviator stress, axial strain and excessive pore water pressure; and b) typical summarized $S_{\mathrm{d}}-$ log $\left(N_{\mathrm{c}}\right)$ relations (Tatsuoka et al., 1991) 

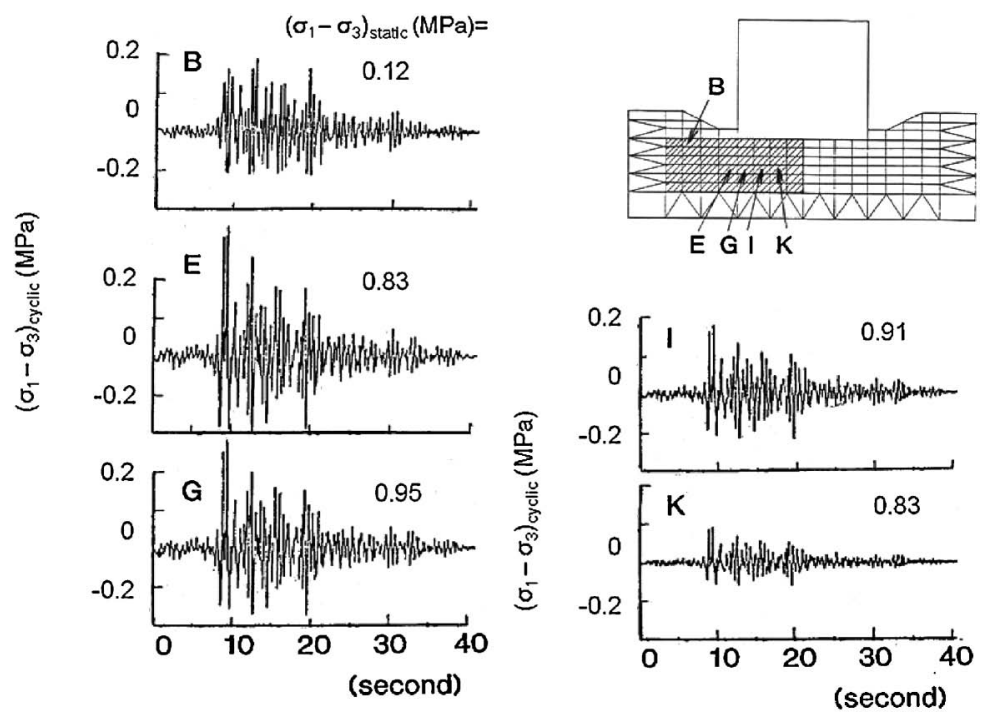

Fig. 16. Typical result from dynamic response analysis at Pier 2P site (Tatsuoka et al., 1991)

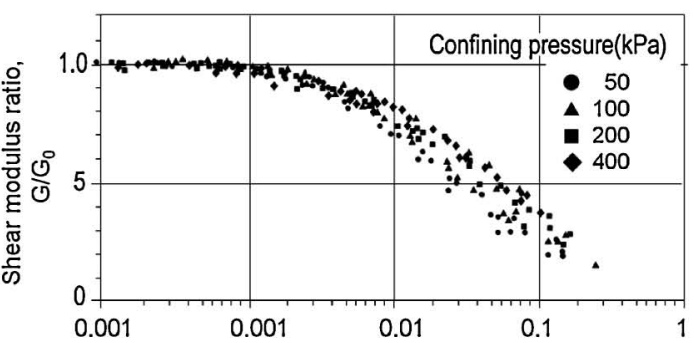

a)

Shear strain (single amplitude, \%)

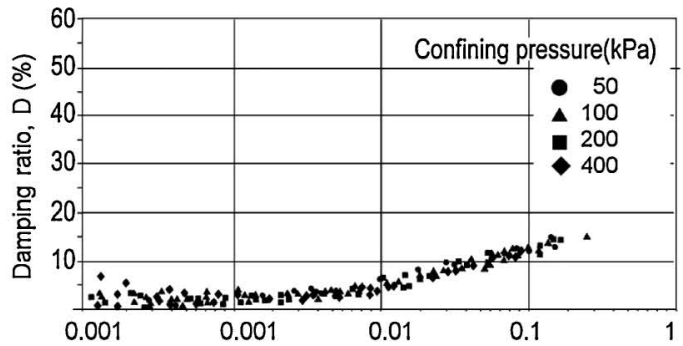

b)

Shear strain (single amplitude, \%)

Fig. 17. Strain-dependent secant shear modulus and damping ratio (Akashi gravelly soil)

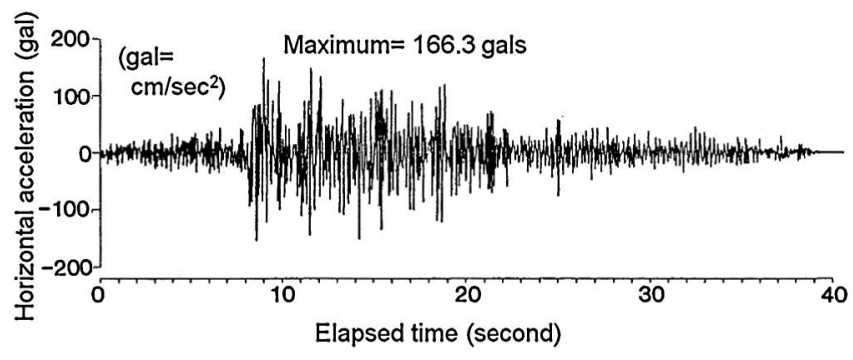

Fig. 18. Design earthquake motion

19(a)), the total damage $D=\Sigma\left[1 /\left\{2 N_{\mathrm{c}}(\mathrm{n})\right\}\right]$ for respective selected values of $\varepsilon_{1}^{+}$was computed, where $N_{\mathrm{c}}(\mathrm{n})$ is the number of cycle at which the $\varepsilon_{1}^{+}$value takes place by the cyclic stress SR(n) obtained from the strength curve, as shown in Fig. 15(b), prepared for different initial effective stress states. This step was repeated by multiplying all half pulses by different factors of $\alpha$ until the total damage $D$ becomes unity. Then, the value of $\alpha \cdot \operatorname{SR}(1)$ for which $D$ $=1.0$, denoted as $[\operatorname{SR}(1)]_{D=1}$, is obtained for the given value of $\varepsilon_{1}^{+}$. This step is repeated by changing the values of $\varepsilon_{1}^{+}$until the relationships presented in Fig. 19(b) are obtained for all concerned soil elements. Fourthly, the value of $\varepsilon_{1}^{+}$obtained by substituting $[\mathrm{SR}(1)]_{D=1}=\mathrm{SR}(1)$ to the relation for respective elements is the residual strain that would take place during the given design earthquake. Figure 20 shows the distributions of this potential strain, which may not satisfy the strain compatibility in the ground. Lastly, in the respective elements, the equivalent secant Young's modulus equal to the ratio of the peak value of $\left(\sigma_{1}-\sigma_{3}\right)_{\text {cyclic }}$ to the value $\varepsilon_{1}^{+}$obtained as above was obtained. Then, a pseudo-static FEM analysis, which satisfies the strain compatibility, was performed using the inertial force that would be activated in the respective elements at the moment of the maximum input horizontal acceleration (i.e., a conservative assumption). The result showed that the maximum relative residual horizontal displacement between the top and bottom of Pier $2 \mathrm{P}$ would be about $2.4 \mathrm{~cm}$, which was about $1 / 3.5$ of the allowable limit. Although the method described above is an approximate one, the line of thought was that several assumptions that were adopted were on the conservative side as a whole, therefore, this result is a clear indication that Pier 2P has sufficient seismic stability.

Another concern was whether the ultimate strength would substantially decrease by cyclic undrained loading during a given earthquake. Figure 21(b) shows a decrease in the undrained TC strength with an increase in the maximum strain encountered after a number of loading cycles 


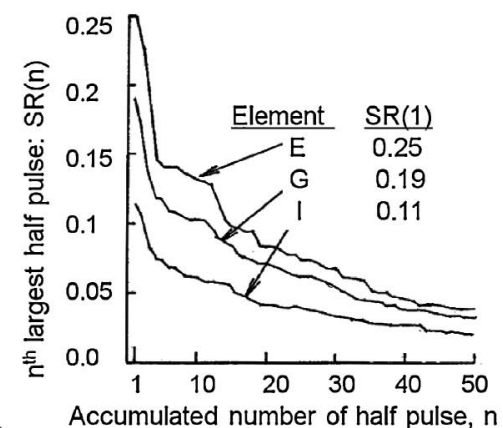

a)

Fig. 19. a) Typical accumulated half pulses of peak deviator stress; and b) SR(1) $)_{D=1}-\varepsilon_{1}^{+}$relations for elements $\mathbf{E}$, G and I (see Fig. 16) (Tatsuoka et al., 1991)

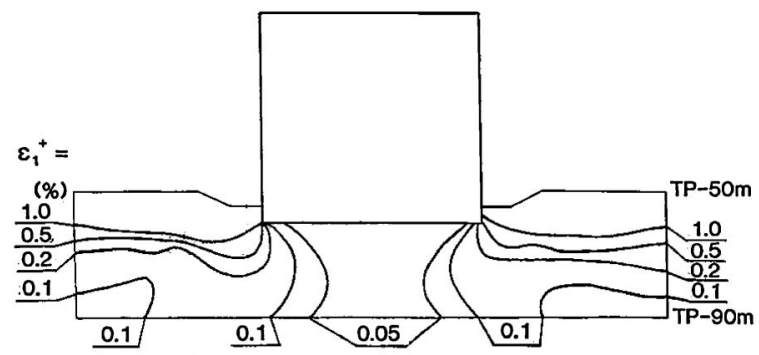

Fig. 20. Potential residual strain $\varepsilon_{1}^{+}$in the ground for the design earthquake motion (Tatsuoka et al., 1991)

(equal to 500) obtained from the test results presented in Fig. 21(a). The decrease is slight, which indicates that such a catastrophic failure of the foundation, as would not take place with a foundation constructed on a saturated loose sand deposit, would take place.

\section{Seismic Response Analysis of the Foundation and Ground}

To obtain the input motion for the dynamic response analysis of the super-structure, the dynamic behaviour of the foundations were evaluated by the following dynamic FEM analysis by taking into account the strain-nonlinearity of the stress-strain behaviour of the geomaterials (Fig. 22). Unlike the one described in Fig. 16, the dynamic interaction between the foundation and the ground was taken into account as follows. A one-dimensional equivalent linear seismic response analysis of the supporting ground when subjected to the design seismic load (Fig. 18) was performed based on the shear wave velocities evaluated by in-situ PS logging while using the strainnon-linearity of the stiffness and the damping ratio of the geomaterials (Fig. 17). Then, the equivalent shear wave velocities and damping ratios corresponding to a shear strain equal to 0.65 times the maximum shear strain in the respective soil layers were obtained. Then, an equivalent homogenous ground with the same natural period as the one of the multiple layer ground under the given seismic loading condition was obtained. Then, a foundation- ground system model was obtained by dealing with the foundation as a rigid rectangular prismatic object with two degrees of freedom (i.e., rocking and swaying). The frequency-dependent stiffness values of $k_{1}$ and $k_{2}$ of the 'springs' were determined on the basis of the elastic wave theory, which can express wave transmission between the foundation and the ground.

\section{POST-CONSTRUCTION BEHAVIOUR}

\section{Footing Settlements}

The following three types of footing displacement were among the major concerns at the design stage: 1) instant settlement by the construction of the superstructure including the tower; 2) the long-term residual settlement by static sustained loads after the construction of the superstructure; and 3) seismic displacements (rotation and settlement). It was considered that, if the instant settlement is very large, the settlements of the second and third types would be too large, although some amount of inclination and settlement at the crest of the foundations due to the instant settlement before the construction of the tower could be alleviated by adjusting the dimensions of the connection at the bottom of the tower. For this reason, the first issue was also considered important. The creep deformation until the end of the design life time (100 years) was calculated by a linear five-component model comprised of an elastic component connected in series to two linear Voigt models (each comprised of another elastic component connected in parallel to a linear viscous component) connected in series. The model parameters of Akashi gravelly soil were evaluated by drained triaxial creep tests and those of Kobe SSR by undrained triaxial creep tests (Yamagata et al., 1995b). The FEM analysis showed that the creep displacements that would take place were allowable. It should be noted that a more realistic model, a non-linear three-component model comprising three components with respectively specific highly non-linear properties for geomaterials has been proposed only recently (e.g., De Benedetto et al., 2002; Tatsuoka et al., 2002, 2008).

Figures 23(a) and (b) show the time-histories of settle- 


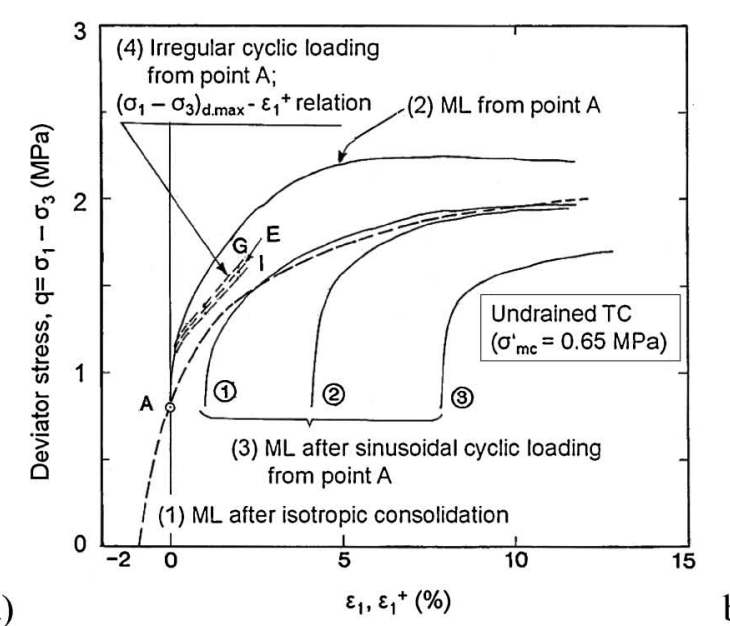

a)

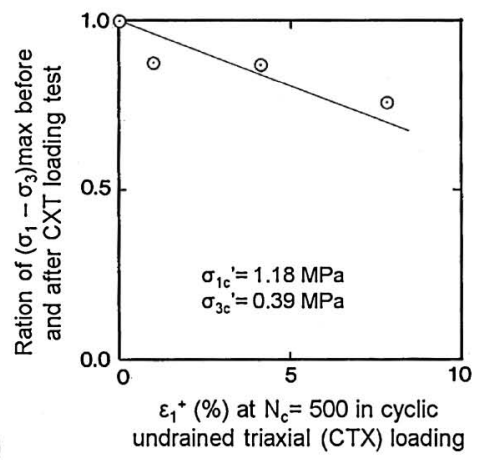

Fig. 21. a) Stress-strain relations from undrained TC tests before and after cyclic undrained loading; and b) decreasing ratio of undrained TC strength by cyclic undrained loading (Tatsuoka et al., 1991)

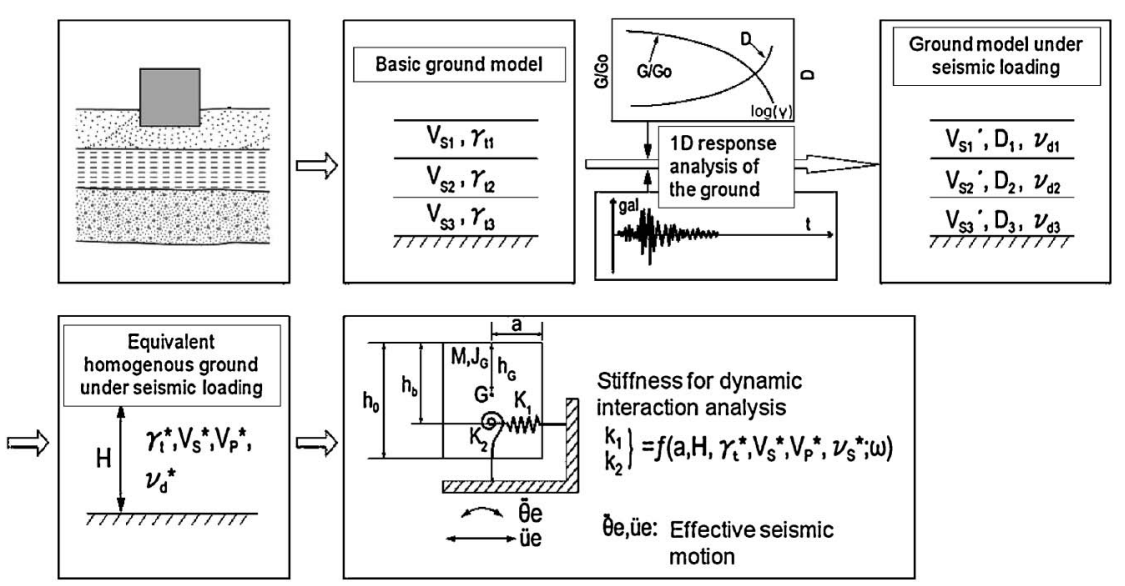

Fig. 22. Modeling procedure of dynamic ground/foundation interaction

ment of Piers 2P and 3P. The major component of the settlement is instant. Figures 24(a) and (b) show the relationships between the average contact pressure at the pier base (p) ave and the pier settlement $S$ for a nearly full period of construction. Their FEM simulations are explained later. The fact that the recorded relations are rather linear does not mean that the stress-strain properties of the geomaterials constituting the supporting ground are linear elastic. In actuality, the ground deformation is highly irreversible and the apparent linear behaviour is due to the balance between the decrease in stiffness with the increase in the strain and an increase in stiffness with an increase in the vertical stress associated with the foundation construction.

It can be seen from Fig. 24(b) that the linear theory using the average Young's modulus $E_{50}$ from unconfined compression tests using core samples from the site of Anchorage $1 \mathrm{~A}$, which is deemed to be of the same order of the magnitude as the value at the site of Pier $3 \mathrm{P}$, gives an extreme over-estimate of the actual settlement of Pier 3P. Although it is to a lesser extent, the linear theory using the average Young's modulus $\left(E_{\mathrm{PMT}}\right)$ from the conven- tional pressure-meter tests (PM tests) performed at the site of Pier 3P also over-estimates the actual settlement by a significant amount. These two potential problems were already recognized at the design stage, and the Young's modulus $\left(E_{\mathrm{PLT}}\right)$ from plate loading tests (PL tests) was thought to be much more reliable. As it was not possible to perform PL tests at the site of Pier 3P, the values of $E_{\mathrm{PLT}}$ were estimated from the $E_{\mathrm{PMT}}$ values measured at the Pier 3P site based on an empirical correlation between $E_{\mathrm{PLT}}$ and $E_{\mathrm{PMT}}$ obtained by performing these tests at an on-shore site with ground conditions similar to those at the 3P Pier site (Yamagata et al., 1995a). The empirical equation shows that the ratio $E_{\mathrm{PLT}} / E_{\mathrm{PMT}}$ becomes larger and exceeds unity as $E_{\mathrm{PMT}}$ becomes smaller.

It should be noted, however, that obtaining design parameters by PL tests is not as straightforward as it may appear. That is, the PL tests that provided the most reliable data of Akashi SSR were those performed using a rigid plate with a diameter of $60 \mathrm{~cm}$ on a Akashi SSR deposit exposed at the bottom of excavation for Anchorage A1 at a depth of about $60 \mathrm{~m}$ (Fig. 25). Among the four PL tests, the other three tests besides test S-2 ex- 


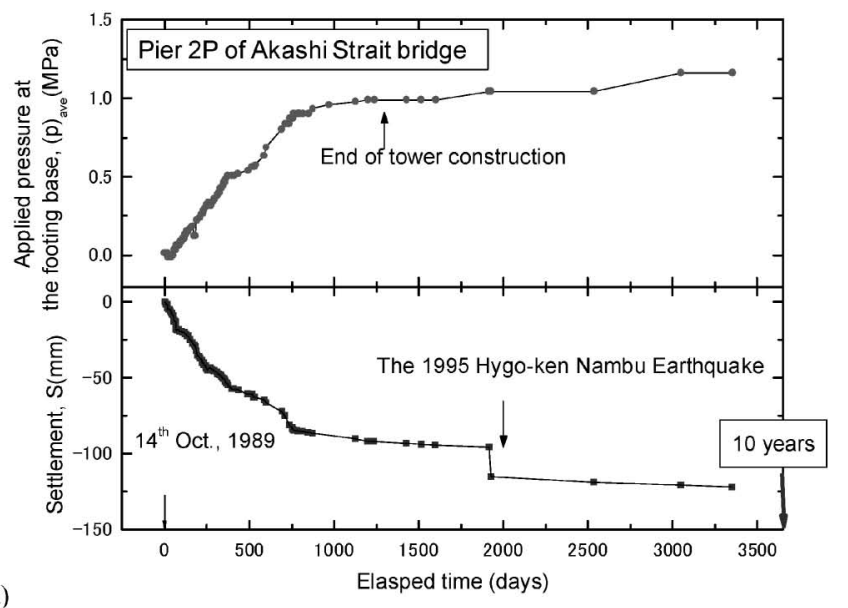

a)

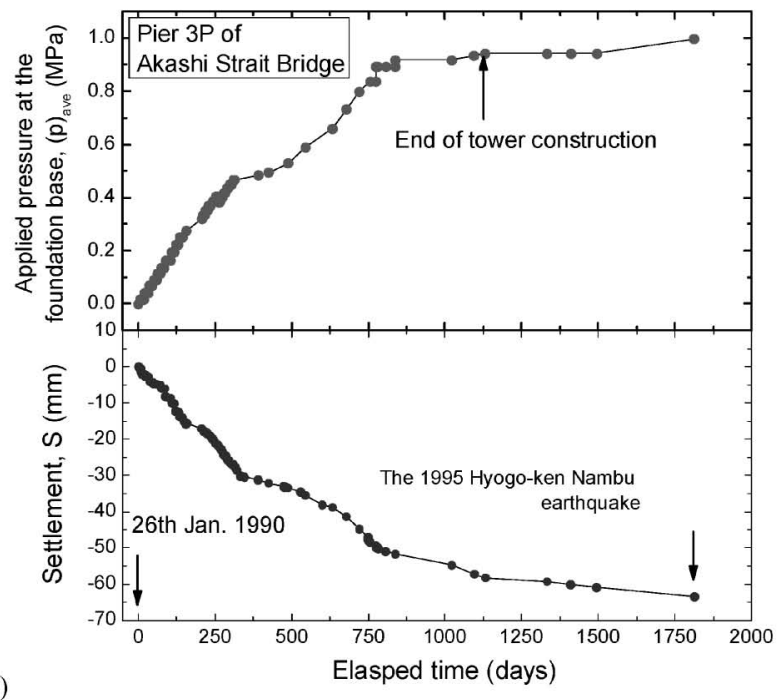

Fig. 23. Time history of settlement: a) 2P; and b) 3P, Akashi Strait Bridge (Tatsuoka et al., 2001) hibited very similar results. Test S-2 exhibited an extremely soft response, very likely due to joints opened by ground excavation. The ( $)_{\text {ave }}-S$ relations are highly non-linear with the tangent stiffness $\mathrm{d}(\mathrm{p})_{\text {ave }} / \mathrm{d} S$ increasing with $(\mathrm{p})_{\text {ave }}$. This trend is because an increase in the tangent stiffness with an increase in $(p)_{\text {ave }}$ is stronger than a decrease with an increase in the strain. The stiffness from the initial primary loading curve is too small, due mainly to very low initial pressure and bedding errors. The average $E_{\text {PLT }}$ value from the secant modulus until (p) ave becomes about $2 \mathrm{MPa}$ is $306 \mathrm{MPa}$, which is similar to the average $E_{\mathrm{PMT}}$ value $(=283 \mathrm{MPa})$ at the site (Fig. 10$)$. It may be seen from Fig. 24(b) that the linear theory using this $E$ value over-estimates by a factor of about three the measured settlement of Pier 3P. The engineering judgment and the decision taken at the design stage based on experience was right: the use of Young's modulus $E_{\text {PLT }}$ from the secant stiffness $E_{\mathrm{s}}$ associated with unload/reload curve, as shown in Fig. 25, was more appropriate, as this Young's modulus is only slightly smaller than $E=1.0$ $\mathrm{GPa}$, back-calculated by the linear theory from full-scale behaviour (Fig. 24(b)). However, there is no logical reason to use this Young's modulus to predict the footing settlement for which no cyclic loading with a large load amplitude as applied in the PLT tests is applied. Moreover, this value is also similar to a Young's modulus from the tangent stiffness for ( $\mathrm{p})_{\text {ave }}$ largely exceeding the actual maximum ( $\mathrm{p})_{\text {ave }}$ value of Pier $3 \mathrm{P}$ (about $1 \mathrm{MPa}$ ). This experience indicated again that the $E_{\mathrm{PLT}}$ value in fact is affected too much by the arbitrary effects of bedding errors, pressure levels, loading rate, manner of cyclic loading and so on for this to be a reliable design parameter. The FEM simulation presented in Fig. 25 is explained later.
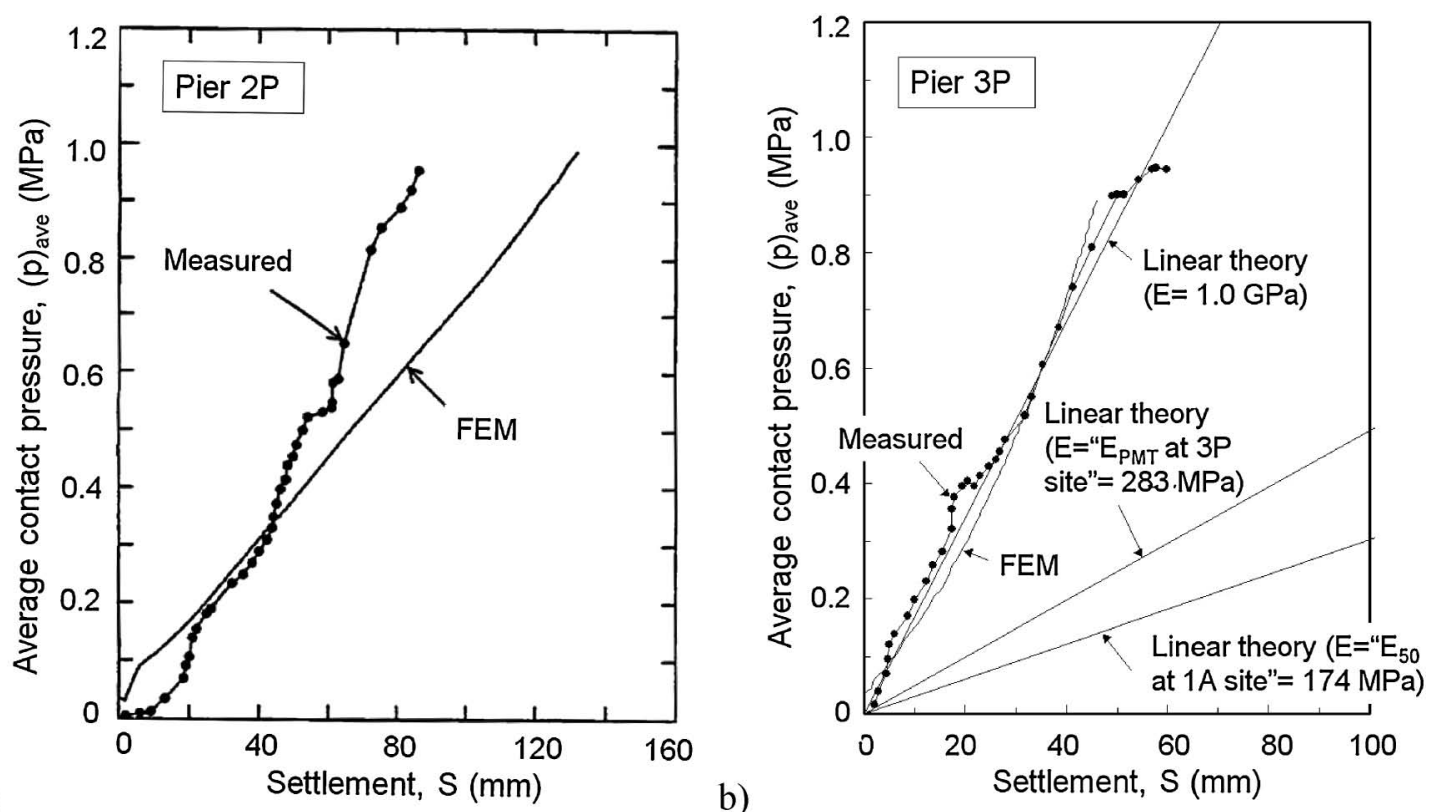

Fig. 24. Contact pressure-settlement relation: a) 2P; and b) 3P, Akashi Strait Bridge (Tatsuoka et al., 2001) 


\section{Relationship between Operated Stiffness and Strain}

Figure 26 shows the center-line vertical strains in the ground of Kobe gravelly soil, Akashi SSR and granite below Piers $2 \mathrm{P}$ and $3 \mathrm{P}$ at an intermediate construction stage. The ground strains are generally very small, below about $0.5 \%$. This trend can be explained by the design of the foundations which allowed a limited amount of displacement while they were being constructed on relatively stiff ground (although the ground conditions were the worst in the Honshu-Shikoku connection bridge network). It may also be seen that strain decreases rapidly

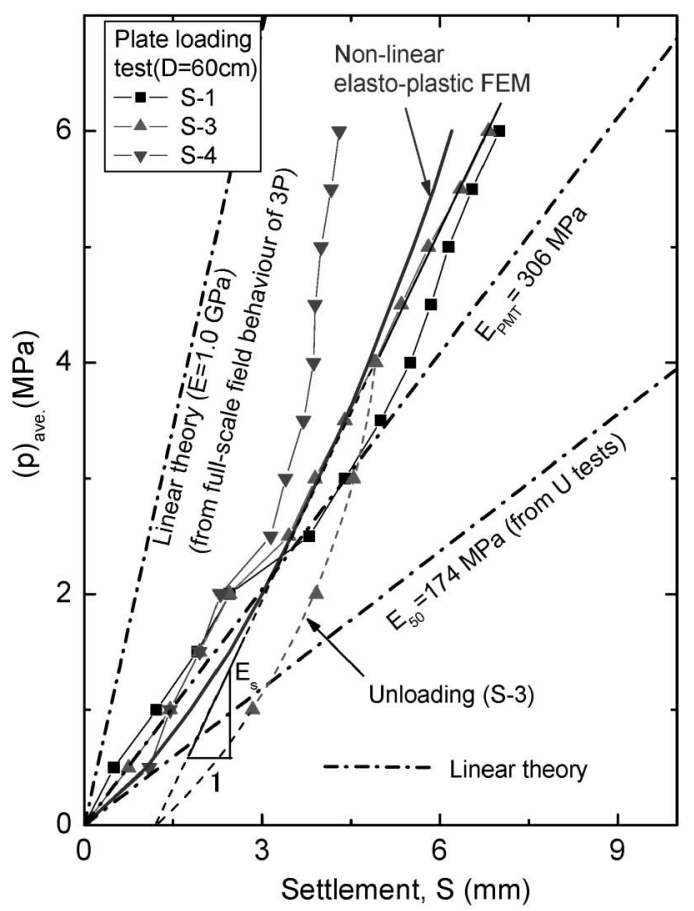

Fig. 25. Pressure-settlement relations from four PL tests using a 60 cm dia.-rigid plate at Anchorage 1A and relations predicted by linear theories and FEM analysis (Tatsuoka et al., 1999) with depth. Figure 27 shows the values of the secant Young's modulus $\left(E_{\mathrm{FEM}}\right)$ at different depths back-calculated by a linear 3D FEM using measured ground strains and known footing loads when (p) ave was about a half the final value (about 1.2 MPa) (Yoshida et al., 1993). These $E_{\mathrm{FEM}}$ values divided by the respective corresponding elastic Young's modulus values $\left(E_{\mathrm{f}}\right)$ from the field shear wave velocities measured before construction are plotted against measured ground vertical strains $\varepsilon_{1}\left(=\varepsilon_{\mathrm{v}}\right)$. The filed data points scatter more as $\varepsilon_{1}$ decreases, mainly because the accuracy of the field data decreases as $\varepsilon_{1}$ decreases. The numerals indicated next to each data point are the numbers of the sub-layers counted from the top. The data from the conventional PM tests performed at the sites are also plotted. As the strain levels in the PM

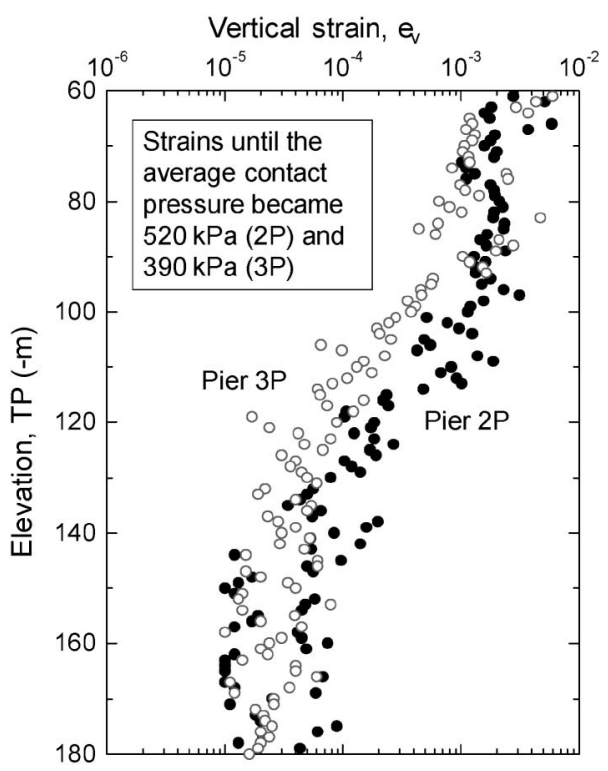

Fig. 26. Centre-line vertical strains in the ground below Piers $2 P$ and $3 P$ (Takeuchi et al., 1997)

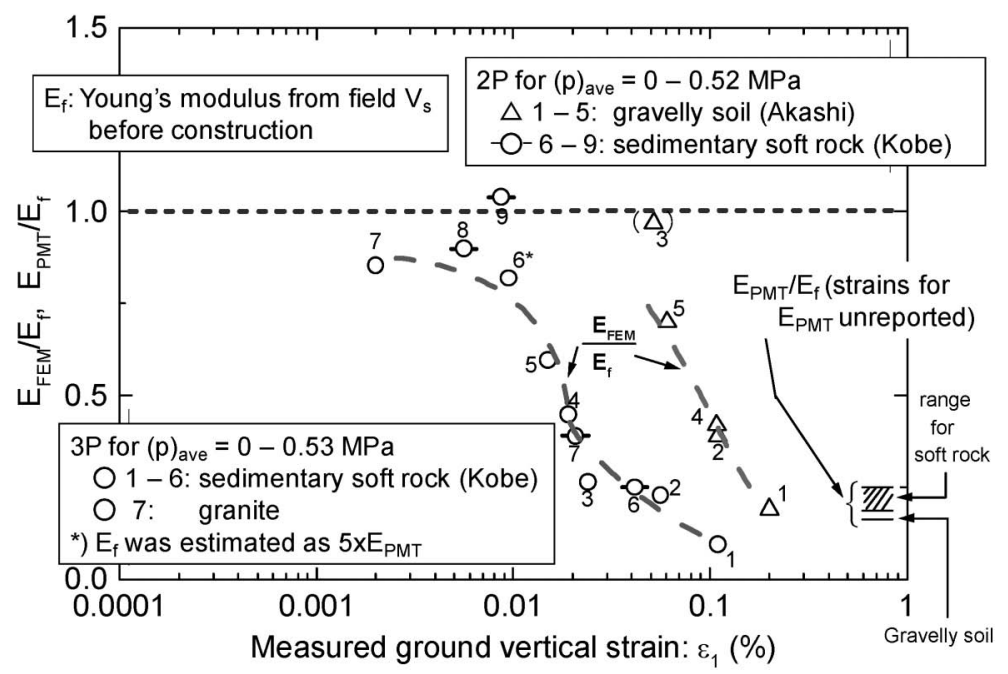

Fig. 27. Relationships between back-calculated Young's modulus and measured ground strain and Young's modulus values for PM tests (Tatsuoka and Kohata, 1995) 
tests are not reported, by referring to similar test results, the ratios $E_{\mathrm{PMT}} / E_{\mathrm{f}}$ are plotted arbitrarily at $\varepsilon_{1}=0.7 \%$. The following trends of behaviour may be noted. Firstly, two separated well-defined relations for Kobe SSR and granite and for Akashi gravelly soil are seen. In particular, a single relation for Kobe SSR and granite common for Piers $2 \mathrm{P}$ and $3 \mathrm{P}$ is obtained. Secondly, as $\varepsilon_{1}$ approaches $0.001 \%$, the ratio $E_{\mathrm{FEM}} / E_{\mathrm{f}}$ tends to approach unity. This indicates that the ground deformation and structural displacements can be predicted based on shear wave velocities when properly taking into account the strain- and pressure-non-linearity of stiffness. Thirdly, the relations are highly non-linear, and this is more noticeable than in the case of those obtained from the TC laboratory tests (Tatsuoka and Kohata, 1999). This is because the observed non-linearity is due to not only strainnon-linearity but also pressure-nonlinearity. That is, the $E_{\mathrm{FEM}}$ values at higher strains are those at shallower depths, where the decrease in the initial pressure was larger by ground excavation to a depth of $14 \mathrm{~m} \mathrm{(2P)} \mathrm{and} 19 \mathrm{~m}$ (3P). These stiffness values may have decreased also by disturbance during ground excavation. Lastly, the $E_{\mathrm{PMT}}$ values from the conventional pre-bored PM tests with an linear interpretation of primary loading curves are similar to the smallest values of $E_{\mathrm{FEM}}$ at the largest strains. This is due very likely to large strains involved in the PM tests, as well as the large effects of wall disturbance and bedding error at the bore hole wall face.

With respect to the second and third terms, a large pressure level-dependency of stiffness was observed in cyclic triaxial tests on core samples of Akashi gravelly soil and CD TC tests of core sample of Kobe SSR. In the latter, the $E_{0}$ value (defined for an axial strain of the order of $0.001 \%$ ) increases in proportion to $\sigma_{1}^{0.73}$ (Kohata et al., $1994)$. Moreover, the values of $E_{\mathrm{PMT}}$, which were measured before the ground excavation, are those measured after the application of pressure levels much higher than the values that were activated during the foundation construction, during which the ground strains shown in Figs. 26 and 27 were measured. Therefore, if such $E_{\mathrm{PMT}}$ values are used to evaluate ground deformation and structural displacements, these values should be corrected for both strain- and pressure-non-linearity.

In Figs. 24 and 25, the (p) ave $-S$ relations by non-linear $3 \mathrm{D}$ FEM simulation are presented. In these FEM analyses, the initial Young's modulus $\left(E_{0}\right)$ before the ground excavation in each soil layer was equal to $E_{\mathrm{f}}=2\left(1+v_{\mathrm{u}}\right) \cdot \rho$. $V_{\mathrm{S}}^{2}$, where $\rho$ is the total density; $v_{\mathrm{u}}$ is the undrained elastic Poisson's ratio $(=0.46)$ and $V_{\mathrm{s}}$ is the in-situ shear wave velocity. The dependency of $E_{\tan }$ on strain and pressure was evaluated by triaxial tests. Inherent isotropy and stress-induced anisotropy were assumed for elastic parameters. A fully drained condition during footing construction and PL tests was assumed by using a drained Poisson's ratio $v_{\mathrm{d}}=0.2$ for both gravelly soil and SSR. The settlement evaluated by assuming the fully undrained condition is slightly smaller than the values obtained by assuming fully drained conditions (Siddiquee et al., 1994, 1995). It may be seen that the FEM analysis

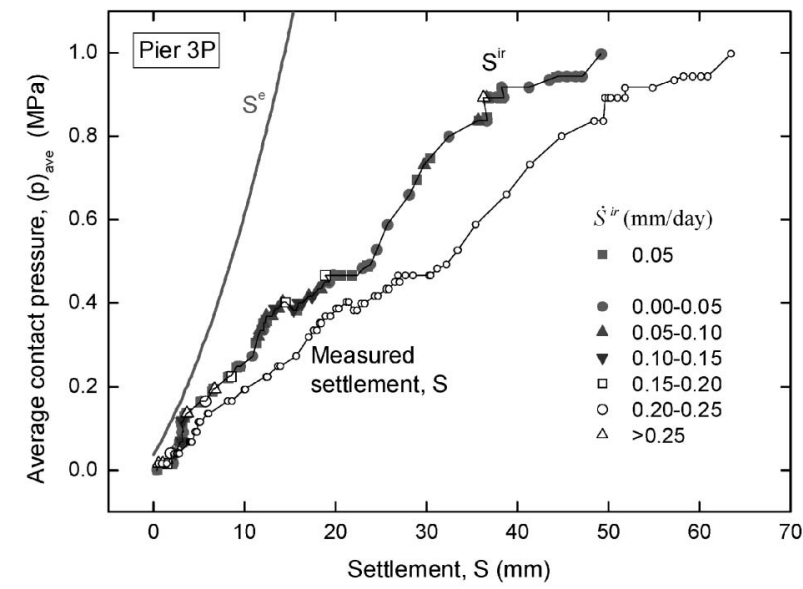

Fig. 28. Decomposition of settlement to elastic and irreversible components, Pier 3P (Tatsuoka et al., 2001)

simulates both the full-scale behaviour of the foundations and the PL tests much better than the linear theory using the $E_{\mathrm{PMT}}$ and $E_{50}$ values. Moreover, the concave shape of the measured relations is simulated by the FEM analysis. This shape can be attributed to the fact that the elastic deformation occupies a large part of the ground deformation, while the elastic Young's modulus increases with pressure. Figure 28 shows the relationships between (p) ave and the total, elastic and irreversible settlements ( $S$, $S^{\mathrm{e}}$ and $S^{\mathrm{ir}}=S-S^{\mathrm{e}}$ ) of Pier 3P, for which the elastic part was obtained by the FEM analysis based on a hypo-elasticity model (Tatsuoka et al., 1999, 2001). The parameters of the model were determined based on the field shear wave velocities measured at the site and the pressure-dependency of the elastic Young's modulus $E_{0}$ evaluated by triaxial tests on core samples. A similar result was also obtained with Pier $2 \mathrm{P}$ (Tatsuoka et al., 2001).

The fluctuation seen in the relationships between $(\mathrm{p})_{\text {ave }}$ $-S$ (or $S^{\text {ir }}$ ) in Fig. 28 is not due to simple measurement errors, but it is due basically to the viscous property of the ground. That is, the tangential slope was small when the construction was slow and vice versa, and the stiffness became very large immediately after construction was restarted at a normal speed following a period of construction stop.

\section{Discussions}

With a huge suspension bridge such as Akashi Strait Bridge, the accurate prediction of the displacements of the foundations is one of the crucial design factors. This is because the construction cost of a foundation, which occupies a large part of the total cost (about 50\% in this case), depends largely on its dimensions and the depth of the foundations, which largely depends on estimated footing displacements. Indeed, a reduction more than $10 \%$ of construction cost would be very difficult with the super-structure, since the remaining room of uncertainty is already very small. In contrast, a larger reduction in the construction cost of the foundations becomes possible 
Table 1. Experiences from recent case histories of foundations for long suspension bridges

\begin{tabular}{l|l|c|c|c|c}
\hline \multicolumn{1}{c|}{ Bridge } & $\begin{array}{l}\text { Geomaterial type of } \\
\text { supporting ground }\end{array}$ & $\begin{array}{c}\text { Strain-dependency } \\
\text { of stiffness }\end{array}$ & $\begin{array}{c}\text { Pressure-dependency } \\
\text { of stiffness }\end{array}$ & $\begin{array}{c}\text { Effects of discontinuities } \\
\text { on ratio } G^{\mathrm{f}} / G_{0}\end{array}$ & References \\
\hline Rainbow in Tokyo & $\begin{array}{l}\text { Sedimentary soft rock } \\
\text { (SSR) (mudstone) }\end{array}$ & Significant & Insignificant & Insignificant & $\begin{array}{l}\text { Izumi et al. (1995); } \\
\text { Tatsuoka et al. (1995, } \\
1999)\end{array}$ \\
\hline Akashi Strait & $\begin{array}{l}\text { 2P: Gravelly soil } \\
\text { underlain by SSR } \\
\text { (sandstone) } \\
\text { 3P: SSR (sandstone) }\end{array}$ & Significant & Significant & Insignificant & $\begin{array}{l}\text { Tatsuoka \& Kohata } \\
\text { (1995); Tatsuoka et al. } \\
(1999,2001)\end{array}$ \\
\hline Tatara ${ }^{2)}$ & Weathered granite & Significant & Significant & Significant & Tatsuoka et al. (1999) \\
\hline
\end{tabular}

Note: 1) $G^{\mathrm{f}}$ : shear modulus from field shear wave velocity; and $G_{0}$ : initial shear modulus to be used to predict ground deformation and structural displacement

2) One of the suspension bridges of the Honshu-Shikoku Connection Bridge network

when we are more confident with the strength and deformation characteristics of geomaterials constituting the supporting ground. With the Akashi Strait Bridge, a very detailed sophisticated geotechnical investigation, which was rather costly, was warranted.

From the experience of working with the Akashi Strait Bridge, we learned that the stiffness in the field for use in predicting footing displacements can be estimated based on field shear wave velocities while taking into account the strain- and pressure-dependency of stiffness evaluated by relevant laboratory tests, as well as other factors. For foundations constructed on weathered rock, the effects of discontinuities should also be taken into account. Table 1 summarizes some experiences in this respect obtained from recent case histories of foundations for long suspension bridges.

\section{KOBE EARTHQUAKE}

On the 17th of January, 1995, a very severe earthquake with a magnitude of 7.2 on the Richter scale occurred with its epicenter very close to the Akashi Strait Bridge. At that time, the erection of the towers had been completed while the cable squeezing work making the compacted circular cable section was on-going. No deck members had been placed. After the earthquake, careful inspections and surveys revealed that, although the bridge did not receive any serious structural damage, the displacement of the four foundations due to tectonic movement was noticeable (Fig. 29). As a result, the center line of the bridge bent slightly, the spans between Piers $2 \mathrm{P}$ and $3 \mathrm{P}$ and between Pier 3P and Anchorage 4A increased by 0.8 $\mathrm{m}$ and $0.3 \mathrm{~m}$ and the cables, which had been already adjusted to the designed configuration, heaved upward 1.3 $\mathrm{m}$ at the center due to the increase in the span (Fig. 30). This elongation of the span was compensated for by adjustments when fabricating the stiffening girder trusses, which was just underway. Also, the connections of the hanger ropes at the cables were adjusted so that they would become vertical. The underground observation hole along the center line of Pier 3P was sheared by a horizontal displacement of $35 \mathrm{~mm}$ at a depth of TP-61.1 m (Fig. 31), which ceased the measurement of vertical

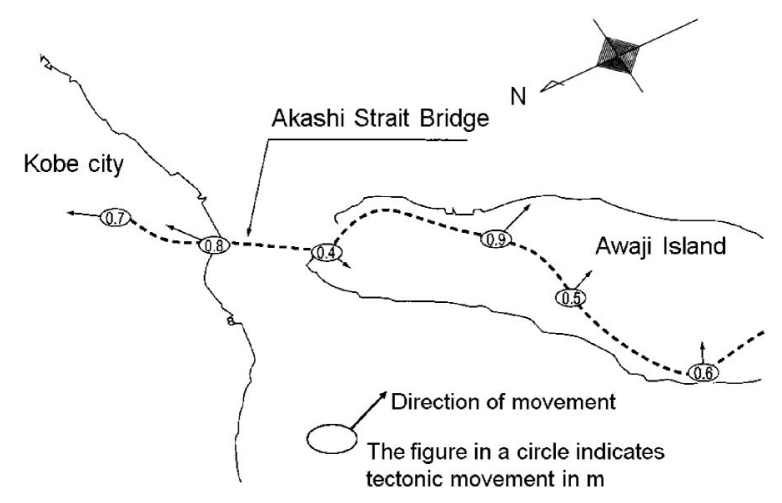

Fig. 29. Tectonic movements of ground during the 1995 Kobe Earthquake (Yoshida and Tada, 1995)
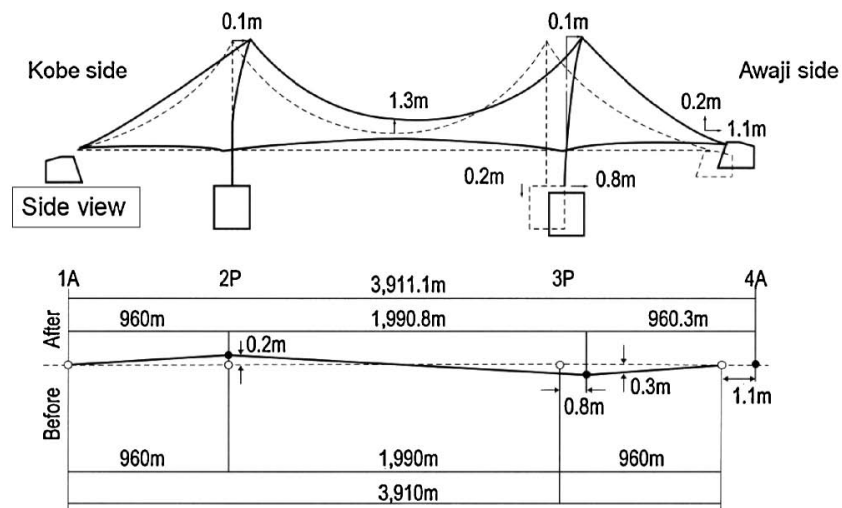

Plan view at the foundation level

Fig. 30. Residual displacements of the bridge relative to Anchorage 1A (Yoshida and Tada, 1995)

displacements in the ground. It was considered that this shear took place by local sliding inside a thin weak mudstone layer in the Kobe SSR stratum.

Pier 2P settled down about $2.0 \mathrm{~cm}$, much less than Pier 3P, due to the earthquake (Fig. 32). The strain in the soil layer just beneath the foundation is $4 \times 10^{-4}$. Only the Akashi gravelly soil deposited was slightly compacted. The vertical distribution of seismic induced residual settlement in the Akashi gravelly soil deposit is rather 
proportional to the one immediately before the earthquake (about 20\%). Fukuoka et al., (2006a, b) reported that the maximum horizontal acceleration at the footing base back-calculated from a time history of velocity measured at the top of the tower on Pier $2 \mathrm{P}$ was about 200 gals. They also showed that a similar value was obtained by an equivalent linear FEM earthquake response analysis which took both the strain-non-linearity of the shear modulus and damping into account using an input time history of horizontal acceleration with a maximum horizontal acceleration of 230 gals at the top of the bedrock of granite. This was obtained by scaling down the observed N55W component with a maximum acceleration of 464 gals observed at the Kobe Marine Meteorological Observation Station during the 1995 Kobe Earthquake. As the maximum horizontal acceleration in the input motion used at the design stage is 166 gals (Fig. 18), it is seen from the above that the prediction made at the design stage that no serious damage to the bridge would take place by the design seismic load is consistent in a broad sense with the actual behaviour.

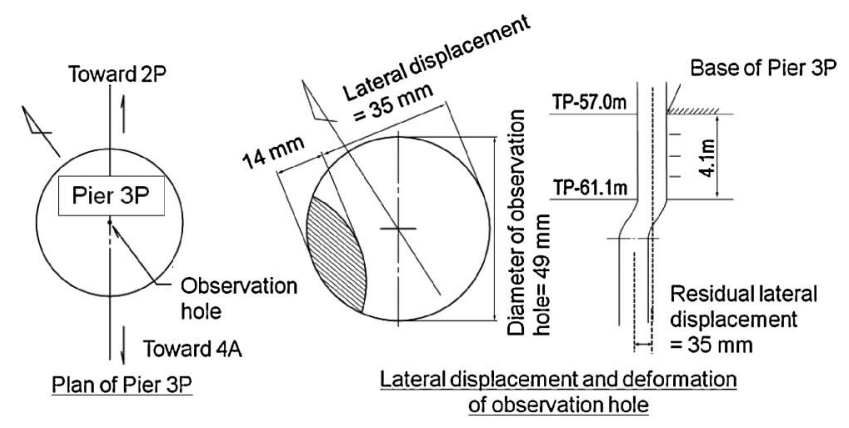

Fig. 31. Deformation of center-line observation hole, Pier 3P (Yoshida and Tada, 1995)

\section{CONCLUSIONS}

For the first time in this project, laboratory stressstrain tests played a very important role in the design of foundations for a huge suspension bridge, while several limitations of traditional geotechnical investigation methods were revealed, as summarized below:

1) Unconfined compression tests on rotary core tube samples largely under-estimated the strength and stiffness of sedimentary soft rock. Advanced triaxial compression (TC) tests provided reliable design parameters. In particular, local measurements of axial strains from very small strains smaller than $0.001 \%$ to about $1 \%$ was necessary to accurately evaluate the stiffness at small strains.

2) CD and CU TC tests and cyclic undrained tests on rotary core tube samples with a diameter of $30 \mathrm{~cm}$ of lightly cemented gravelly soil provided basic data to predict the instant and seismic-induced residual settlements of Pier 2P (on a gravelly soil deposit). A simplified analysis procedure was used to predict the seismicinduced displacements of Pier $2 \mathrm{P}$, the results of which were consistent with the actual behaviour during the 1995 Kobe Earthquake.

3) Large differences in the stiffness values of soil and soft rock were observed between static measurements by laboratory stress-stain tests, pressure-meter tests and plate loading tests and dynamic measurements by field shear wave velocity logging in bore holes. They are due mainly to different levels of strain and pressure, error in strain/displacement measurements, sample disturbance and other factors with large differences involved in these tests. On the other hand, under otherwise the same conditions, the statically measured Young's modulus from triaxial tests is consistent with the value from the field shear wave velocity.

4) The strains in the ground below the foundations were rather small, at about $0.5 \%$ immediately below the footing base and they decreased rapidly with depth.

b)

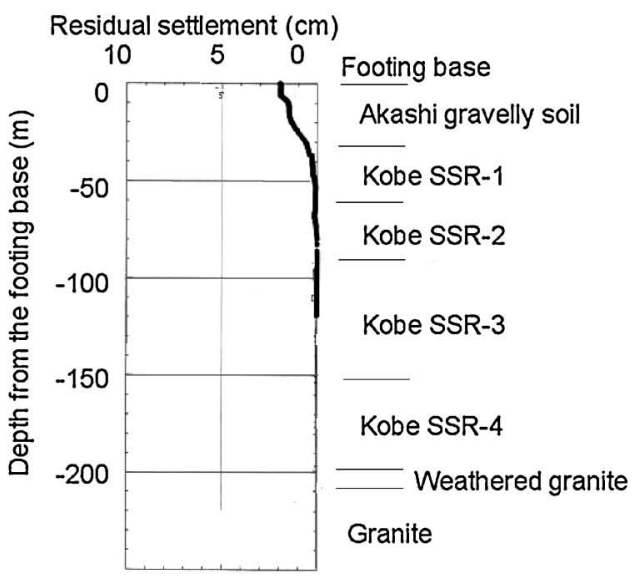

Fig. 32. a) Settlements before and after the 1995 Kobe Earthquake; and residual settlement by the earthquake in the ground beneath Pier $2 P$ (Yoshida and Tada, 1995) 
The stress-strain behaviour of the gravelly soil and sedimentary soft rock below the foundations was highly non-linear by strain and pressure at these small strain levels. The instant settlement of Piers $2 \mathrm{P}$ and $3 \mathrm{P}$ could be simulated by a non-linear 3D FEM analysis using the small strain stiffness determined from the field shear wave velocities and by taking the nonlinearity by the strain and pressure evaluated by triaxial tests on core samples into account.

The foundations were displaced slightly due to the 1995 Kobe Earthquake. The damage was limited. As the bridge construction was underway at that time, the damage was able to be fully recovered by several adjustment works.

\section{REFERENCES}

1) Di Benedetto, H., Tatsuoka, F. and Ishihara, M. (2002): Timedependent deformation characteristics of sand and their constitutive modeling, Soils and Foundations, 42(2), 1-22.

2) Goto, S., Tatsuoka, F., Shibuya, S., Kim, Y.-S. and Sato, T. (1991): A simple gauge for local small strain measurements in the laboratory, Soils and Foundations, 31(1), 169-180.

3) Fukuoka, S., Kamikubo, S., Miyamoto, J., Nakajima, K., Tatsuoka, F. and Koseki, J. (2006a): Re-evaluating the prediction method of residual settlement during the 1995 Kobe Earthquake of Pier 2P of Akashi Strait Bridge, Proc. 61st Annual Conference of Japanese Society for Civil Engineers, III (in Japanese).

4) Fukuoka, S., Kamikubo, S., Miyamoto, J., Nakajima, K., Tatsuoka, F. and Koseki, J. (2006b): Re-evaluating the residual settlement of Pier 2P by the 1995 Kobe Earthquake of Akashi Strait Bridge based on an estimated input earthquake motion, Proc. 61st Annual Conference of Japanese Society for Civil Engineers, III (in Japanese).

5) Izumi, K., Ogiwara, M., Nishida, K. and Kameya, H. (1995): Estimation of ground properties and behaviour under construction of huge suspension bridge, Rock Foundations (eds. by Yoshinaka and Kikuchi), Balkema, 421-426.

6) Kohata, Y., Tatsuoka, F., Dong, J., Teachavorasinskun, S. and Mizumoto, K. (1994): Stress states affecting elastic deformation moduli of geomaterials, Proc. Int. Symposium Pre-Failure Deformation of Geomaterials (eds. by Shibuya et al.), Balkema, 1, 3-9.

7) Siddiquee, M. S. A., Tatsuoka, F., Hoque, E., Tsubouchi, T., Yoshida, O., Yamamoto, S. and Tanaka, T. (1994): FEM simulation of footing settlement for stiff geomaterials, Proc. Int. Symposium Pre-Failure Deformation of Geomaterials (eds. by Shibuya et al.), Balkema, 1, 531-537.

8) Siddiquee, M. S. A., Tatsuoka, F., Kohata, Y., Yoshida, O., Yamamoto, Y. and Tanaka, T. (1995): Settlement of a pier foundation for Akashi-Kaikyo Bridge and its numerical analysis, Rock Foundations (eds. by Yoshinaka and Kikuchi), Balkema, 413-420.
9) Takeuchi, T., Tanaka, T., Yamamoto, S. and Inoue, A. (1997): Akashi Kaikyo Bridge-a case history, Tsuchi-to-Kiso, 45(9), 43-48 (in Japanese).

10) Tatsuoka, F., Maeda, S., Ochi, K. and Fujii, S. (1986): Prediction of cyclic undrained strength of sand subjected to irregular loadings, Soils and Foundations, 26(2), 73-90.

11) Tatsuoka, F., Yamada, K., Yasuda, M., Yamada, S. and Manabe, S. (1991): Cyclic undrained behaviour of an undisturbed gravel for aseismic design of a bridge foundation, Proc. the Second Int. Conf. on Recent Advances in Geotechnical Earthquake Engineering and Soil Dynamics, St. Luois (ed. by Prakash), 1, 141-148.

12) Tatsuoka, F. and Kohata, Y. (1995): Stiffness of hard soils and soft rocks in engineering applications, Proc. Int. Symposium PreFailure Deformation of Geomaterials (eds. by Shibuya et al.), Balkema, 2, 947-1063.

13) Tatsuoka, F., Kohata, Y., Ochi, K. and Tsubouchi, T. (1995): Stiffness of soft rocks in Tokyo metropolitan area-from laboratory tests to full-scale behaviour, Keynote Lecture, Rock Foundation (eds. by Yoshinaka and Kikuchi), Balkema, 3-17.

14) Tatsuoka, F., Jardine, R. J., Lo Presti, D., Di Benedetto, H. and Kodaka, T. (1999): Characterising the pre-failure deformation properties of geomaterials, Proc. XIV IC on SMFE, Hamburg, September 1997, 4, 2129-2164.

15) Tatsuoka, F., Uchimura, T., Hayano, K., Di Benedetto, H., Koseki, J. and Siddiquee, M. S. A. (2001): Time-dependent deformation characteristics of stiff geomaterials in engineering practice, Proc. the Second International Conference on Pre-failure Deformation Characteristics of Geomaterials, Torino, 1999, (eds. by Jamiolkowski et al.), Balkema, 2, 1161-1262.

16) Tatsuoka, F., Ishihara, M., Di Benedetto, H. and Kuwano, R. (2002): Time-dependent shear deformation characteristics of geomaterials and their simulation, Soils and Foundations, 42(2), 103-129.

17) Tatsuoka, F., Di Benedetto, H., Enomoto, T., Kawabe, S. and Kongkitkul, W. (2008): Various viscosity types of geomaterial in shear and their mathematical expression, Soils and Foundations, 48(1), 41-60.

18) Yamagata, M., Nitta, A. and Yamamoto, S. (1995a): Design and its evaluation through displacement measurements for the Akashi Kaikyo Bridge, Rock Foundation (eds. by Yoshinaka and Kikuchi), Balkema, 35-46.

19) Yamagata, M., Yamadao, S., Nishigaki, Y. and Matsumura, S. (1995b): Creep characteristics of the Kobe Formation of Miocene in Tertiary period, Rock Foundation (eds. by Yoshinaka and Kikuchi), Balkema, 127-132.

20) Yoshida, O., Yamagishi, K. and Nasu, S. (1993): Layer deformation of Akashi Strait Bridge tower foundations: observation and back-analysis, Proc. Domestic Symposium on Utilization of Deep Underground Space, the Japanese Geotechnical Society, 149-156 (in Japanese).

21) Yoshida, I. and Tada, K. (1995): Outline of Southern Hyogo Earthquake $(\mathrm{M}=7.2)$ disasters and behaviours of foundations of the Akashi Kaikyo Bridge, Rock Foundation (eds. by Yoshinaka and Kikuchi), Balkema, 67-72. 